\title{
Prevalence and Impact of Chronic Debilitating Disorders
}

\section{Mark Canney, Triona McNicholas, Siobhan Scarlett and Robert Briggs}

\section{Contents}

Key Findings 152

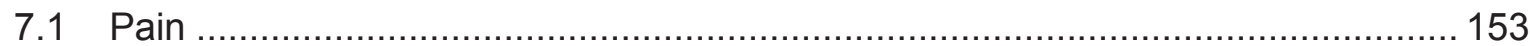

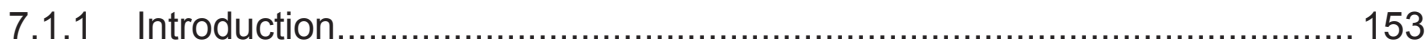

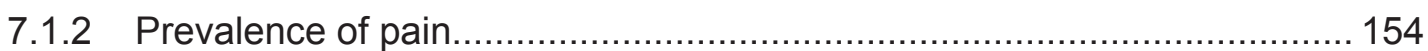

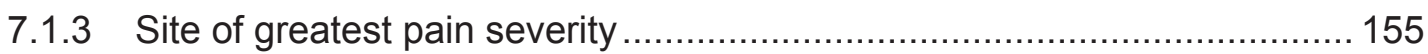

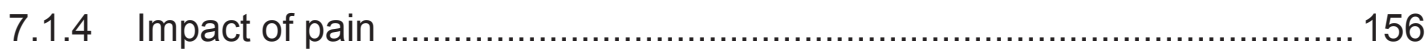

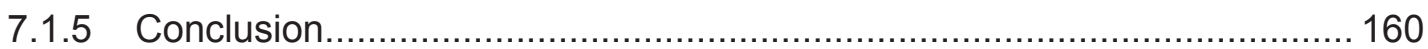

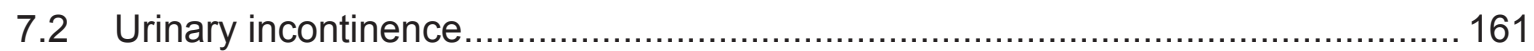

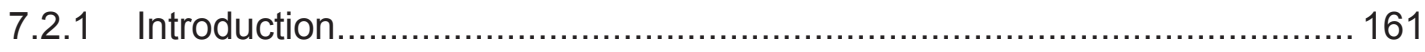

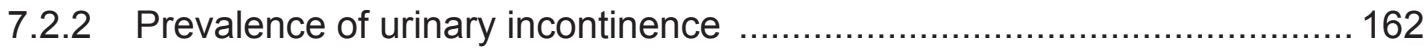

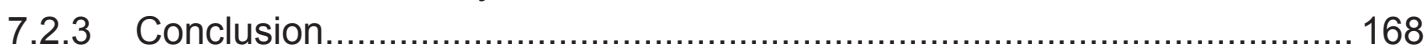

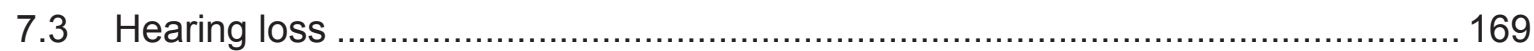

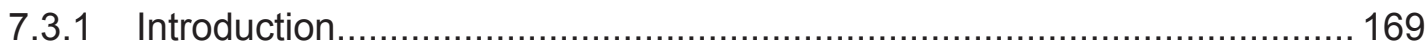

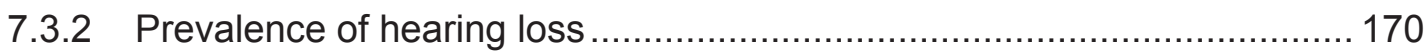

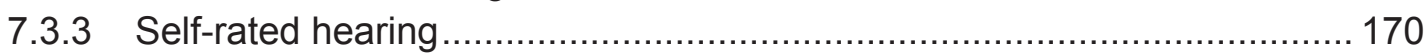

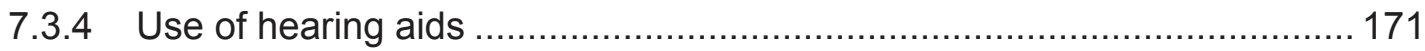

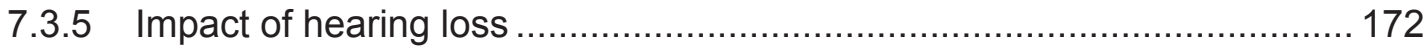

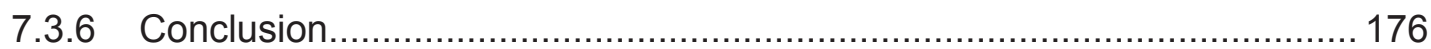

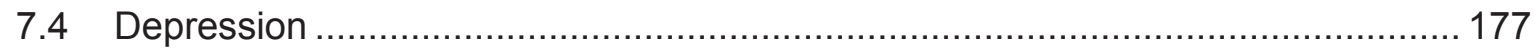

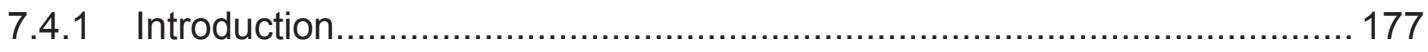

7.4.2 Prevalence of major depressive episode within last 12 months............... 178

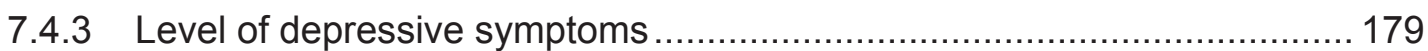

7.4.4 Depressive symptoms, disability and self-rated health .......................... 179

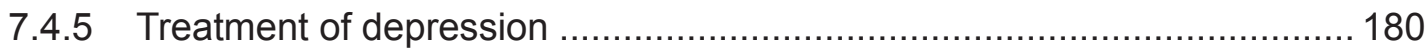

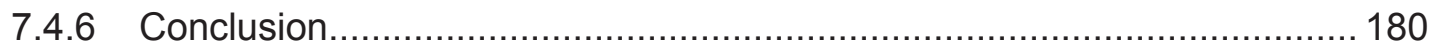

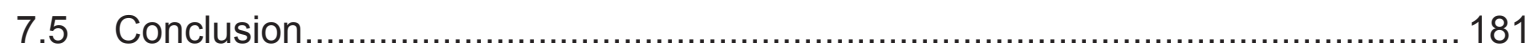

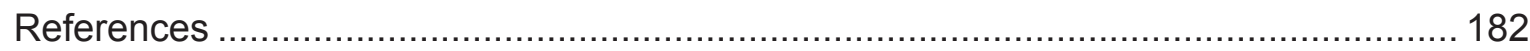

Appendix 7A: Tables on Prevalence and Impact of Chronic Debilitating Disorders ....... 187 


\section{Prevalence and Impact of Chronic Debilitating Disorders}

\section{Key Findings}

- Overall, 1 in 3 older adults in Ireland report being troubled with pain. Back pain is the most common site of pain in both men and women.

- Of those who report any pain, women are more likely to report that they had difficulties with instrumental activities of daily living and this increases with age $(61 \%$ in those aged $54-64$ years versus $68 \%$ in those aged 75 years and over).

- Overall, 1 in 7 older adults in Ireland experience urinary incontinence, with twice as many women as men affected.

- Only 3 out of 5 older adults in Ireland with urinary incontinence have reported their symptoms to a doctor, nurse or other health care professional.

- 1 in 4 older adults in Ireland experience some limitation of their usual activities as a consequence of having urinary incontinence.

- Overall, one third of older adults (36\%) have experienced hearing loss, and it is more common at older ages, exceeding $50 \%$ among individuals aged 75 years and over.

- Despite a high prevalence of self-reported hearing loss, the use of hearing aids is low $(8 \%)$ in the population of adults aged 54 years and over.

- Less than 1 in 3 older people with increased depressive symptoms are prescribed medical treatment for depression. 
This chapter examines the prevalence and impact of chronic debilitating disorders such as pain, hearing loss, urinary incontinence and depression. 6,425 participants aged 54 and over in Ireland participated in Wave 3 of TILDA. The majority of analyses in this section are based on this sample.

\subsection{Pain}

\subsubsection{Introduction}

Pain is increasingly common in older adults. Globally it has been estimated that 1 in 5 adults suffer from pain and that another 1 in 10 adults are diagnosed with chronic pain each year. Pain can be acute, chronic or intermittent, or a combination of all three (1). Chronic pain, defined as pain lasting longer than three months, commonly affects the back and neck (2). Prevalence data on pain varies considerably across different studies. The prevalence of current pain at specific body sites ranges from $20-46 \%$ in studies of community-dwelling older adults (3).

The literature suggests that pain increases with age, however this increase in pain plateaus in the seventh decade with the exception of pain secondary to degenerative joint disease (4). This may reflect a balance between the ageing nervous systems's ability to respond to pain and an increase in the levels of chronic disease that accompanies old age (5). Pain is one of the most common reasons for disability in older adults and is associated with immobility, poorer health status and greater healthcare utilisation $(6,7)$. This highlights the need for effective pain management. Fundamental to appropriate pain management is assessment and diagnosis, which can be challenging due to the subjective nature of pain. This can be even more challenging in older adults due to communication difficulties, sensory or cognitive impairment, or misconceptions about the nature of pain in older people (3).

In TILDA, participants who completed a self-interview ${ }^{1}(n=6,310)$ were asked if they are troubled by pain and if so, they were asked follow-up questions about the severity and duration of pain, the site of greatest severity and whether their pain affects their ability to complete everyday tasks. 2,208 participants reported pain and were asked follow-up questions regarding site and severity of pain.

1 Proxy respondents $(n=115)$ are not asked the series of questions about pain 


\subsubsection{Prevalence of pain}

More than one in three older adults $(36 \%)$ were affected by pain, and this did not vary by age (Table 7.1A). However, in both waves, pain was more common in women than in men (41\% versus $31 \%$ ) (Figure 7.1 ). The level of pain reported at Wave 3 was similar to that reported at Wave 1.

Figure 7.1: Prevalence of pain in Wave 1 and Wave 3 of TILDA, by sex
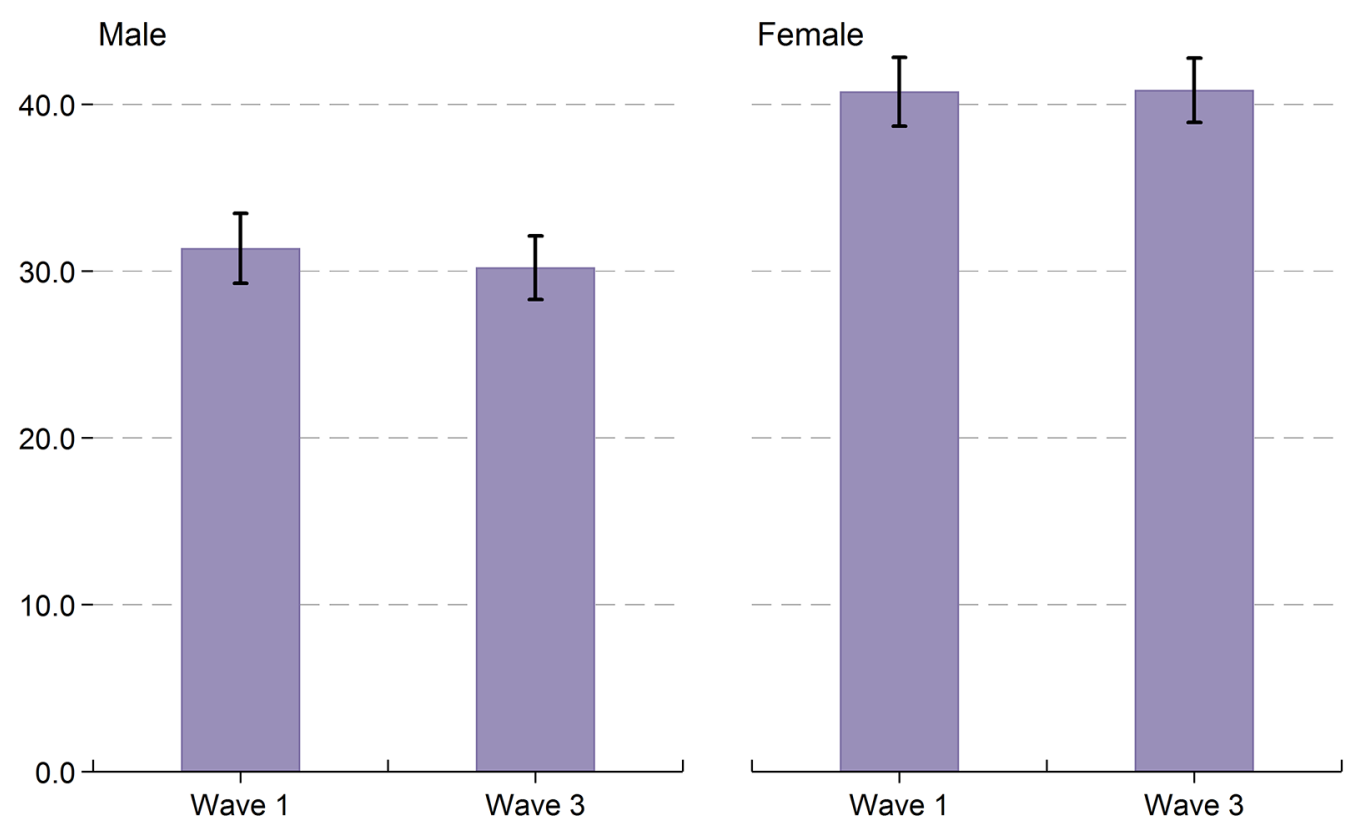

Note. $\mathrm{N}=6160$; Missing obs $=5$; Error bars correspond to $95 \%$ confidence intervals 


\subsubsection{Site of greatest pain severity}

Knowledge of pain location may help to establish the most effective means of pain management. The most common sites of pain are the back (39\%) and knees $(23 \%)$ and hips (16\%) (Table 7.1A). There was little association between age and site of pain, however men aged 65 and over were more likely to report hip pain (20-22\%) compared to men aged 54-64 years (10\%) (Figure 7.2).

Figure 7.2: Prevalence of site of pain with greatest severity by age group and sex

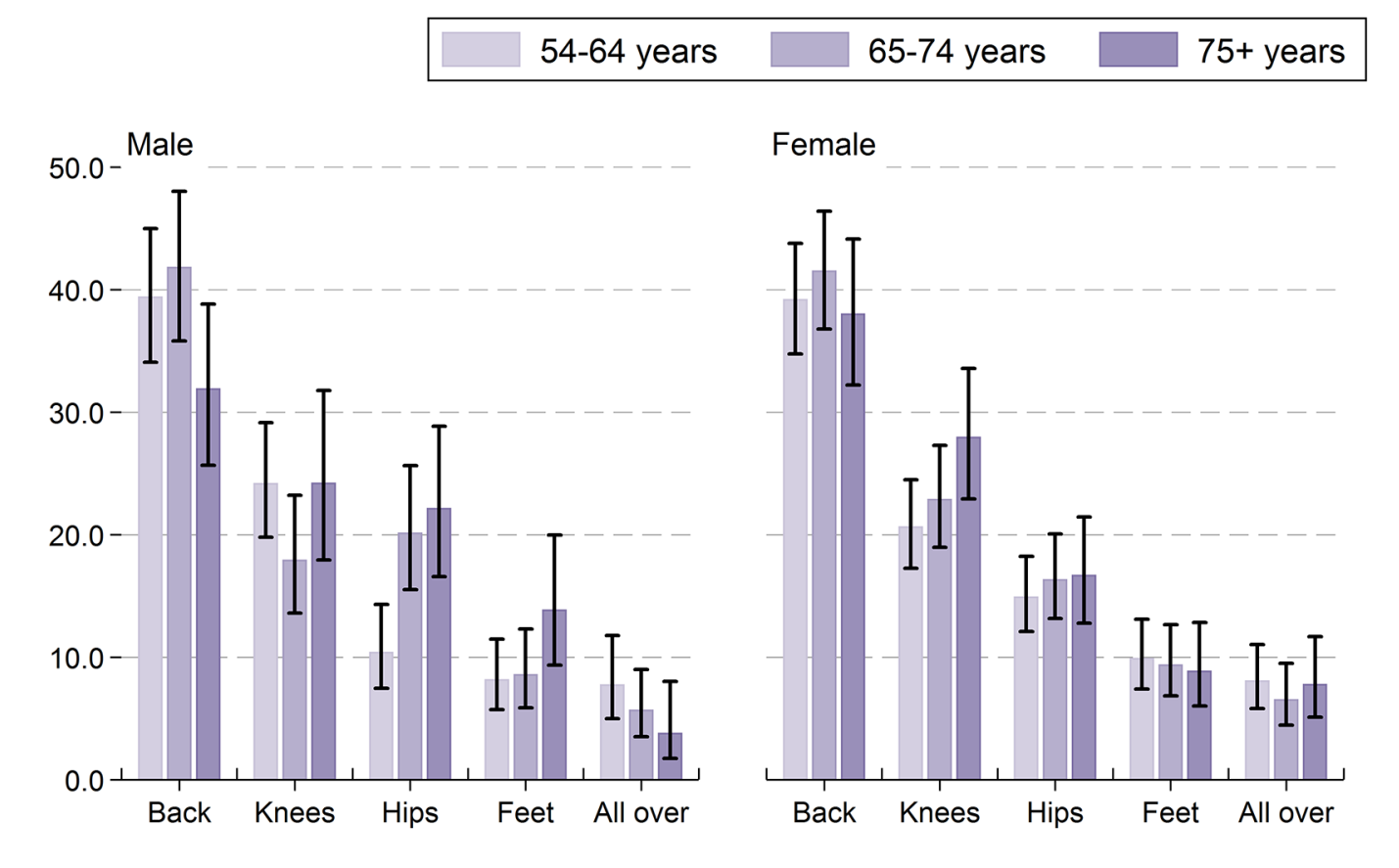

Note. $N=2208$; Missing obs $=0$; Error bars correspond to $95 \%$ confidence intervals

Adults who report that their pain is worst "all over" are most likely to report that their pain interferes with their ability to complete usual activities (77\%). The prevalence of limited activities is relatively similar when examined across all other pain sites: back (68\%), hip (64\%), feet $(63 \%)$ and knee $(62 \%)$. 


\subsubsection{Impact of pain}

\section{Pain and activities of daily living}

Participants were asked if they have any difficulties with basic activities of daily living (ADLs) or instrumental activities of daily living (IADLs), excluding any difficulties expected to last less than three months. ADLs include tasks such as walking, bathing, dressing and eating, while IADLs include tasks such as preparing meals, shopping for groceries and managing medications, all tasks which help support an independent lifestyle. In the older population in Ireland, men and women, who reported having either an ADL disability or both an ADL and IADL disability were more likely to report any pain (Figure 7.3). Women who reported having an IADL disability only were also more likely to report any pain than men $(71 \%$ vs $41 \%)$.

Figure 7.3: Prevalence of any pain, by disability and sex

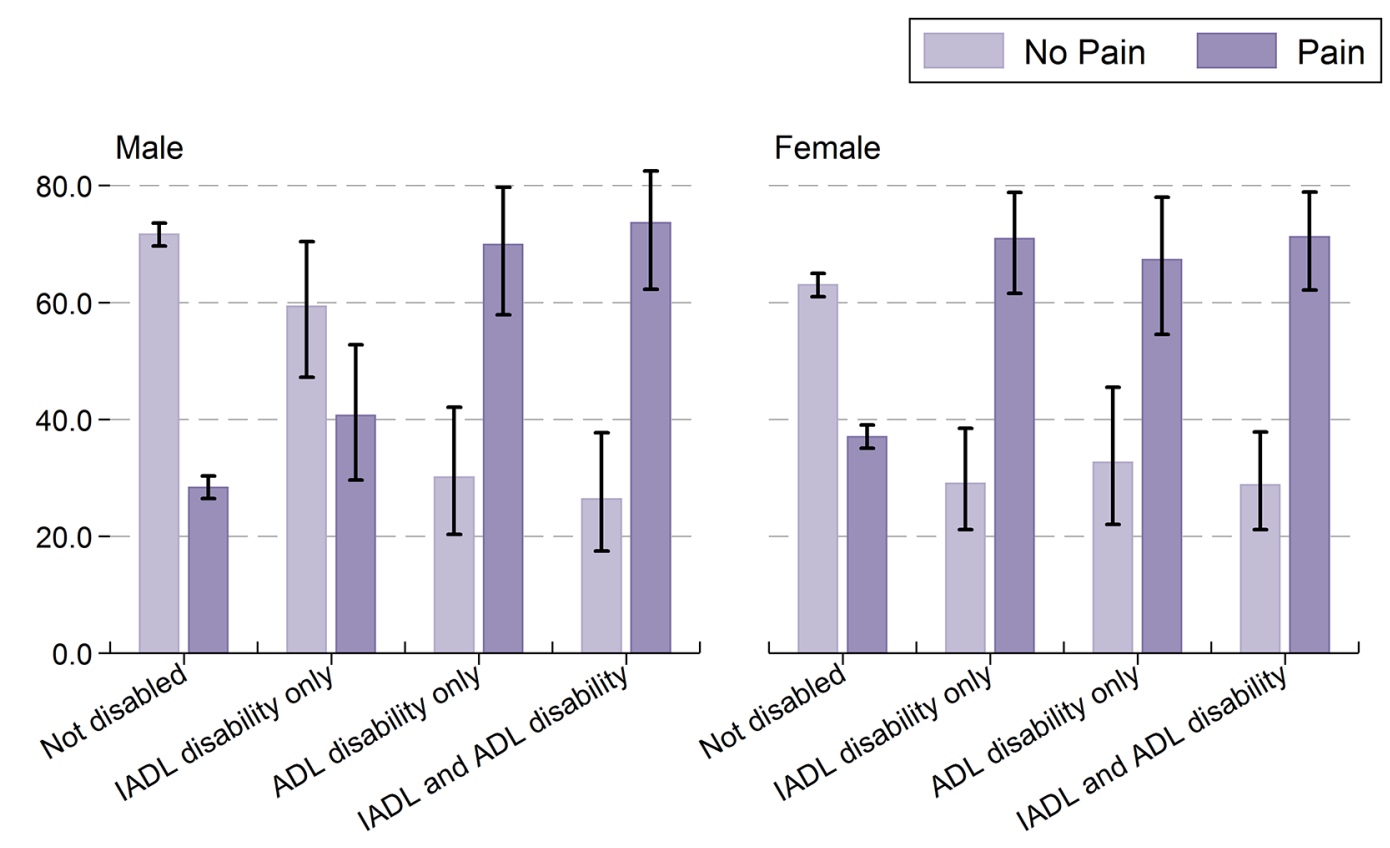

Note. $\mathrm{N}=6305$; Missing obs $=5$; Error bars correspond to $95 \%$ confidence intervals 


\section{Pain and healthcare utilisation}

The mean number of GP visits in the last year in older adults is higher in both men and women who report any pain (5 visits) compared to those not reporting pain (3 visits). This trend was consistent across all age groups (Figure 7.4). Older adults who describe their pain as being worst "all over" visited their GP on average eight times in the last year (Table 7.3A).

Figure 7.4: Mean number of GP visits by any pain, sex and age group

\begin{tabular}{|l|}
$\square$ No pain \\
$\square$ Pain
\end{tabular}
8.0- $^{- \text {Male }}$ Female
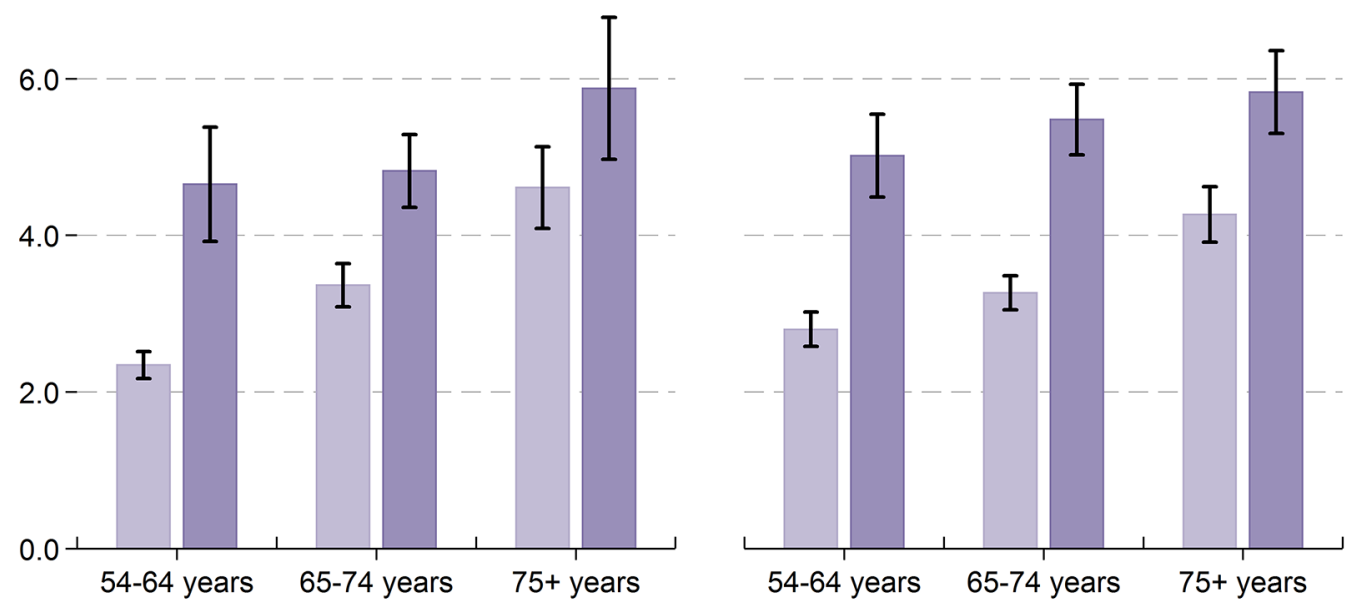

Note. $\mathrm{N}=6290$; Missing obs $=20$; Error bars correspond to $95 \%$ confidence intervals 


\section{Pain and active social participation}

Participants were asked about activities they engage in including going to films, plays or concerts, attending classes or lectures, playing cards, bingo, games in general, going to the pub, eating out of the house, taking part in sport activities or exercise. Those who did any of these activities at least once a week were classified as participating in active social participation.

Within the older Irish population, women who report any pain also report reduced active social participation, compared to those who do not report pain (Figure 7.5).

Figure 7.5: Prevalence of respondents participating in active social participation by any pain, sex and age

\begin{tabular}{|l}
$\square$ No pain $\square$ Pain \\
$\square$
\end{tabular}
$80.0-$ Male

Female
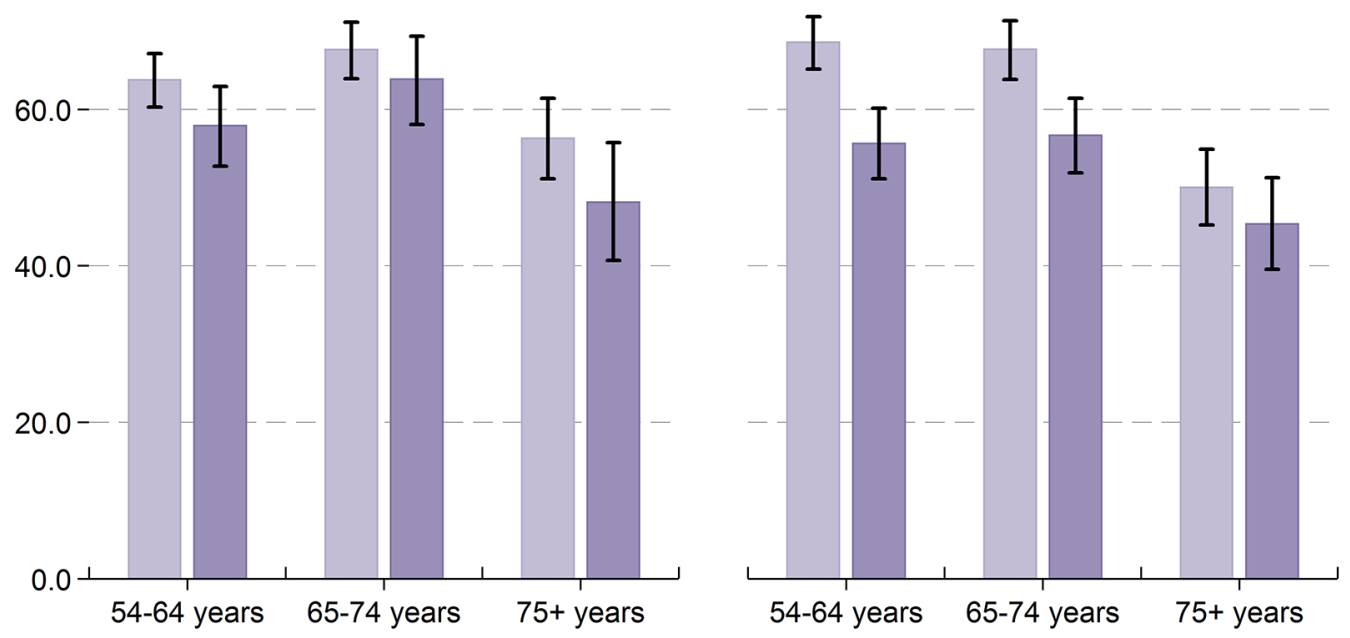

Note. $\mathrm{N}=6304$; Missing obs $=6$; Error bars correspond to $95 \%$ confidence intervals 


\section{Pain and quality of life and self-rated health}

TILDA uses the 12-item self-report measurement, CASP-12, to assess quality of life $(8,9)$. Each item is scored from 0 to 3 and summed to give an overall score (range 0 to 36) with higher scores denoting better quality of life.

Older adults who report pain at Wave 3 have a lower mean CASP-12 quality of life score than those who do not report pain (women: 25 versus 28; men: 25 versus 27 ). This trend is consistent across age groups and in both men and women (Table 7.4A).

Pain also has an impact on self-rated health. Both men and women who report any pain are less likely to rate their health as "Excellent" or "Very good" than those who do not report pain (Figure 7.6).

Figure 7.6: Self-rated health of older adults in Ireland by pain and sex

\begin{tabular}{|l}
$\square$ No pain \\
$\square$ Pain
\end{tabular}
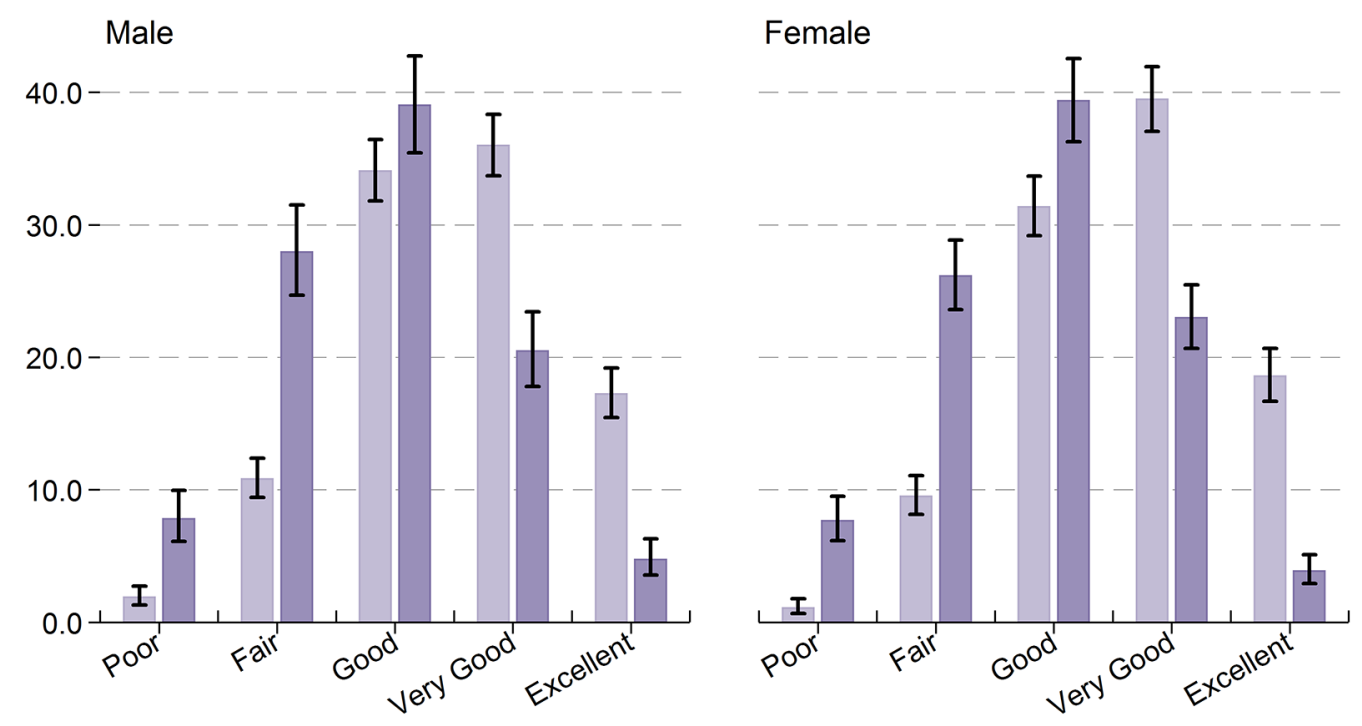

Note. $\mathrm{N}=6304 ;$ Missing obs $=6$; Error bars correspond to $95 \%$ confidence intervals 


\section{Pain and mood}

In Wave 3, TILDA measures depressive symptoms using the 8-item Centre for Epidemiological Studies (CES-D8) depression subscale (10). A higher score on the summed scale indicates higher levels of depressive symptoms (range 0-24). Those who reported any pain scored higher on the CES-D8 than those who reported no pain (5 versus 2 ). Women who reported any pain also scored higher than men (5 versus 4$)$. Both men and women with chronic pain or limiting pain scored 5-6 on the scale, which is higher than the score in those with no pain (Figure 7.7).

Figure 7.7: Mean depressive symptoms score (CES-D8), by presence of pain and sex

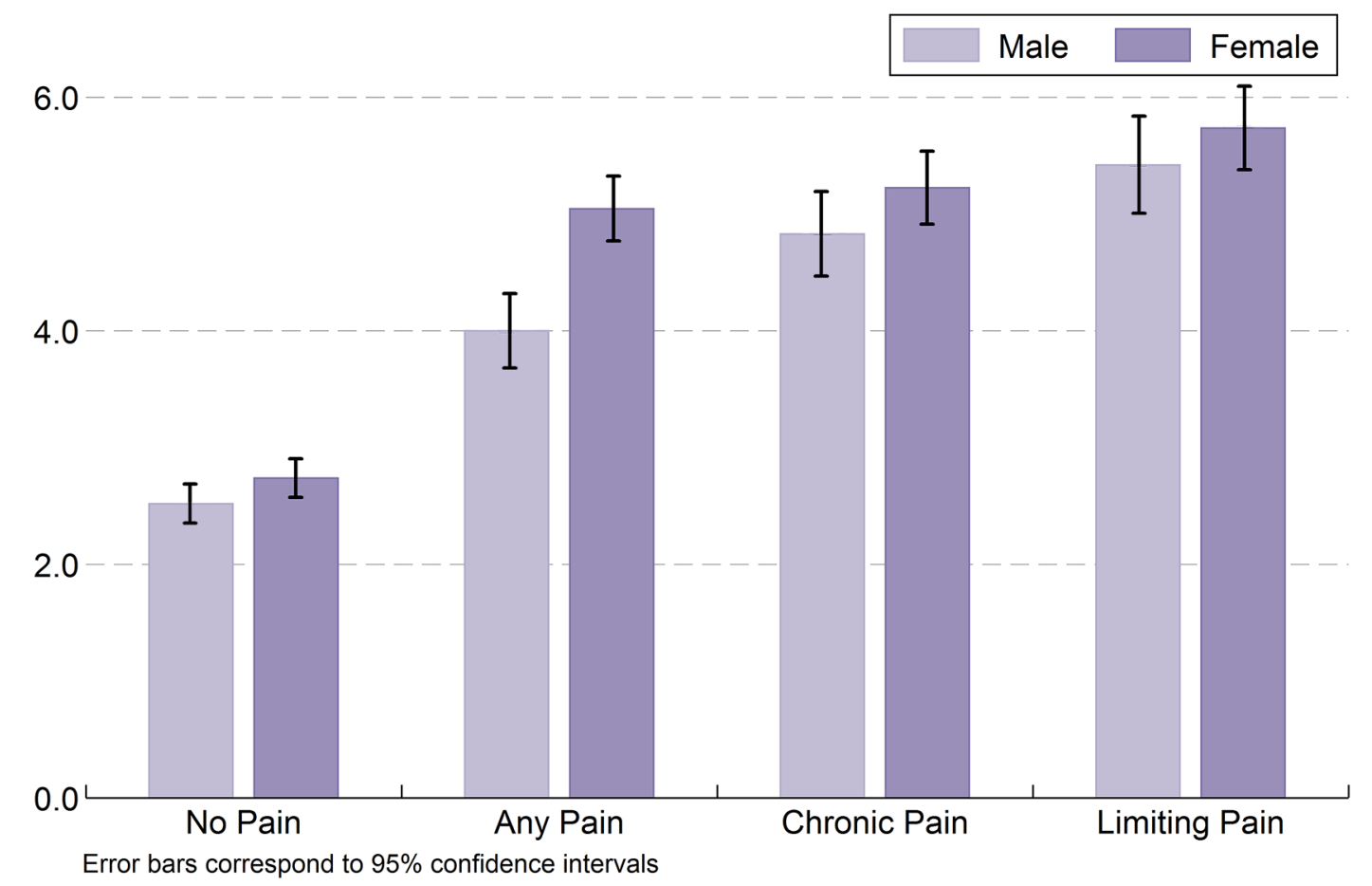

\subsubsection{Conclusion}

Pain affects one in three older adults in Ireland, with the majority of those who experience pain reporting chronic pain. Pain is an important factor affecting disability in older people and this is supported by these findings. Adequate pain management may address some adverse effects associated with pain such as disability, low mood, increased GP utilisation, poor self-rated health and decreased quality of life. 


\subsection{Urinary incontinence}

\subsubsection{Introduction}

Urinary incontinence (UI) describes any involuntary loss of urine from the bladder (11). Previous studies attempting to define the prevalence of UI have differed substantially in terms of study design, definitions of $U I$ and the specific populations studied (12). Furthermore, UI symptoms are under-reported in primary care, due in part to a perception that conditions such as UI are an inevitable consequence of ageing (13). Qualitative interviews with older adults in the community have revealed several barriers to them reporting $\mathrm{UI}$ to their doctor, including lack of awareness about potential treatments, and generational differences in attitudes towards the disclosure of personal or sensitive information (14). This culminates in a lack of information about the true prevalence of UI in the general population of older adults.

There are several reasons why it is important to understand the burden of $\mathrm{UI}$ in the older population. UI contributes to a reduced quality of life and poorer mental health, including greater levels of anxiety (15). Conditions affecting the bladder are highly stigmatising. Individuals experiencing $U \mathrm{I}$ tend to feel embarrassed about their symptoms and can be reluctant to engage in social activities. Importantly, a number of risk factors for $\mathrm{UI}$ are potentially modifiable such as being overweight or smoking. In this section, we describe the breadth and burden of $\mathrm{UI}$ among older adults in Ireland and examine to what extent older Irish people discuss this condition with health care professionals. TILDA participants were asked whether they had experienced $\mathrm{UI}$ in the 12 months prior to their interview and if this had occurred more than once during a one-month period. 


\subsubsection{Prevalence of urinary incontinence}

Overall, 1 in 7 (14\%) older adults in Ireland have experienced UI and the prevalence is two-fold higher in women compared to men (19\% versus $8 \%)$. However, in both sexes, there is a step-wise increase in the prevalence of $\mathrm{UI}$ with increasing age: 1 in 10 adults aged 54 to 64 years; 1 in 7 among those aged 65 to 74 years; and 1 in 5 adults aged 75 years and over. The highest prevalence of $\mathrm{UI}$ is encountered among women aged 75 years and over (28\%) (Figure 7.8).

Figure 7.8: Prevalence of urinary incontinence, by age group and sex

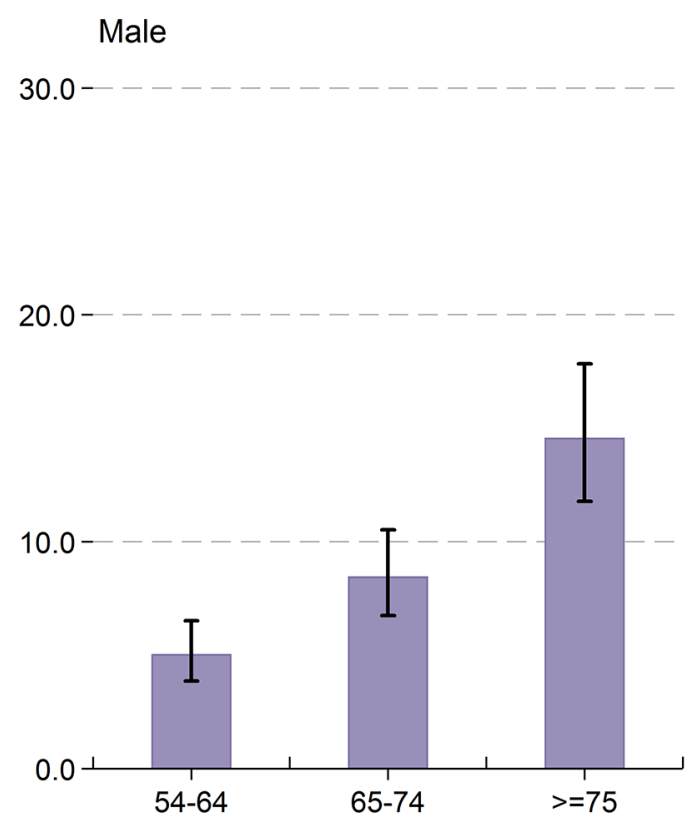

\section{Female}

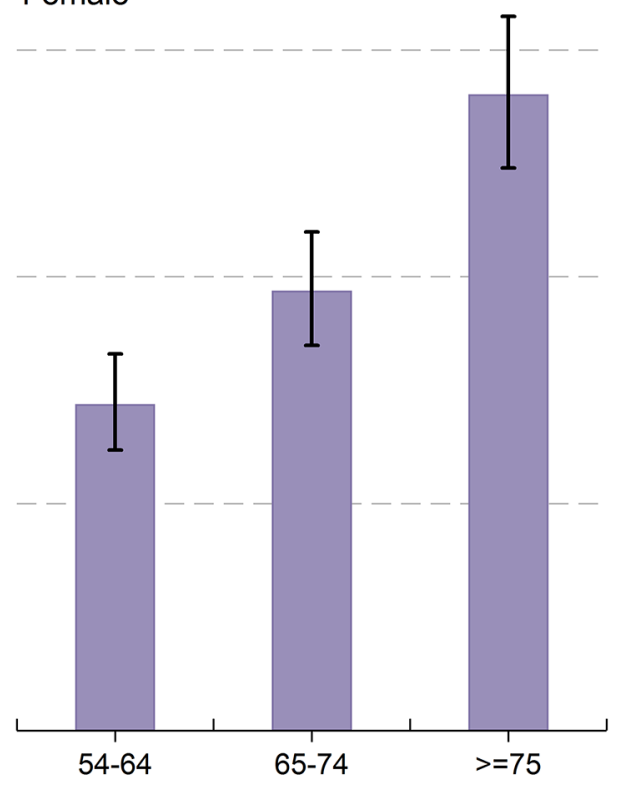

Note. $\mathrm{N}=6410$; Missing obs $=15$; Error bars correspond to $95 \%$ confidence intervals

Among older adults who experience UI, 4 out of every 5 individuals have symptoms more than once per month, and this proportion does not vary substantially by age or sex. 


\subsubsection{Impact of urinary incontinence}

\section{Urinary incontinence and healthcare utilisation}

Individuals with UI have a higher rate of healthcare utilisation compared to those without UI. For example, older people with UI have, on average, two more visits per year to their GP. This increased rate of healthcare utilisation is seen in women of all ages and in men aged less than 75 years (Figure 7.9).

Figure 7.9: Number of GP visits in the past year, by urinary incontinence, age group and sex
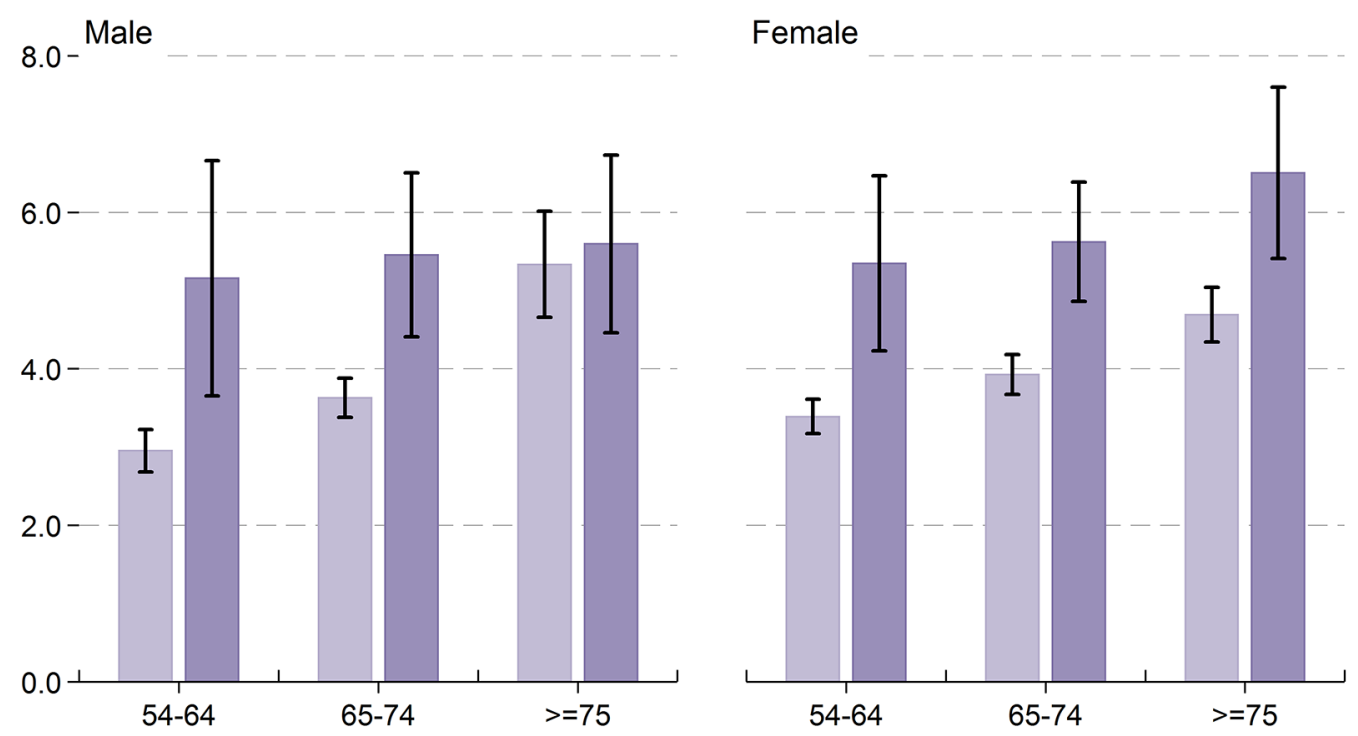

Note. $\mathrm{N}=6388$; Missing obs $=13$; Error bars correspond to $95 \%$ confidence intervals 
Despite the greater interaction with their GP, only two thirds (64\%) of older adults in Ireland with UI report their symptoms to a doctor, nurse or other health care professional. This is comparable to reports from population studies in other countries. Overall, men are more likely to report their symptoms than women $(71 \%$ versus $61 \%)$, however, women are more likely to report their symptoms as they get older (Figure 7.10).

Figure 7.10: Discussion of urinary incontinence with a healthcare professional, by age group and sex
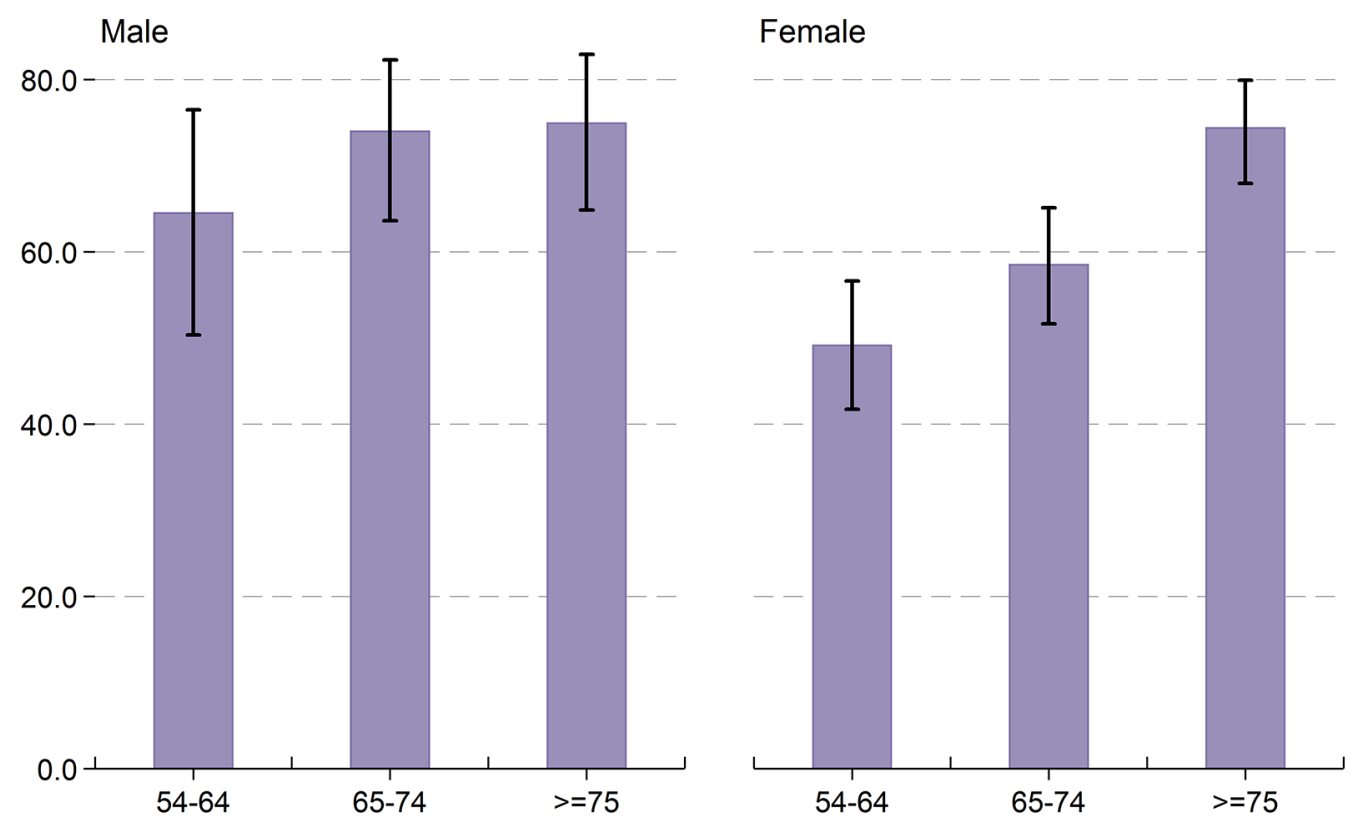

Note. $\mathrm{N}=896$; Missing obs = 5529; Error bars correspond to $95 \%$ confidence intervals

\section{Urinary incontinence and limitation of daily activities}

Overall, one in four older adults in Ireland (28\%) experience some limitation of their usual activities as a consequence of having UI. This proportion does not vary significantly by age or sex. 
Urinary incontinence and active social participation

Individuals experiencing UI are less likely than those without UI (50\% versus $61 \%$ ) to engage in active social participation. This difference, which is similar in men and women, is driven by a particularly low rate of social participation among adults aged 75 years and over with UI (Figure 7.11).

Figure 7.11: Active social participation, by urinary incontinence and age group
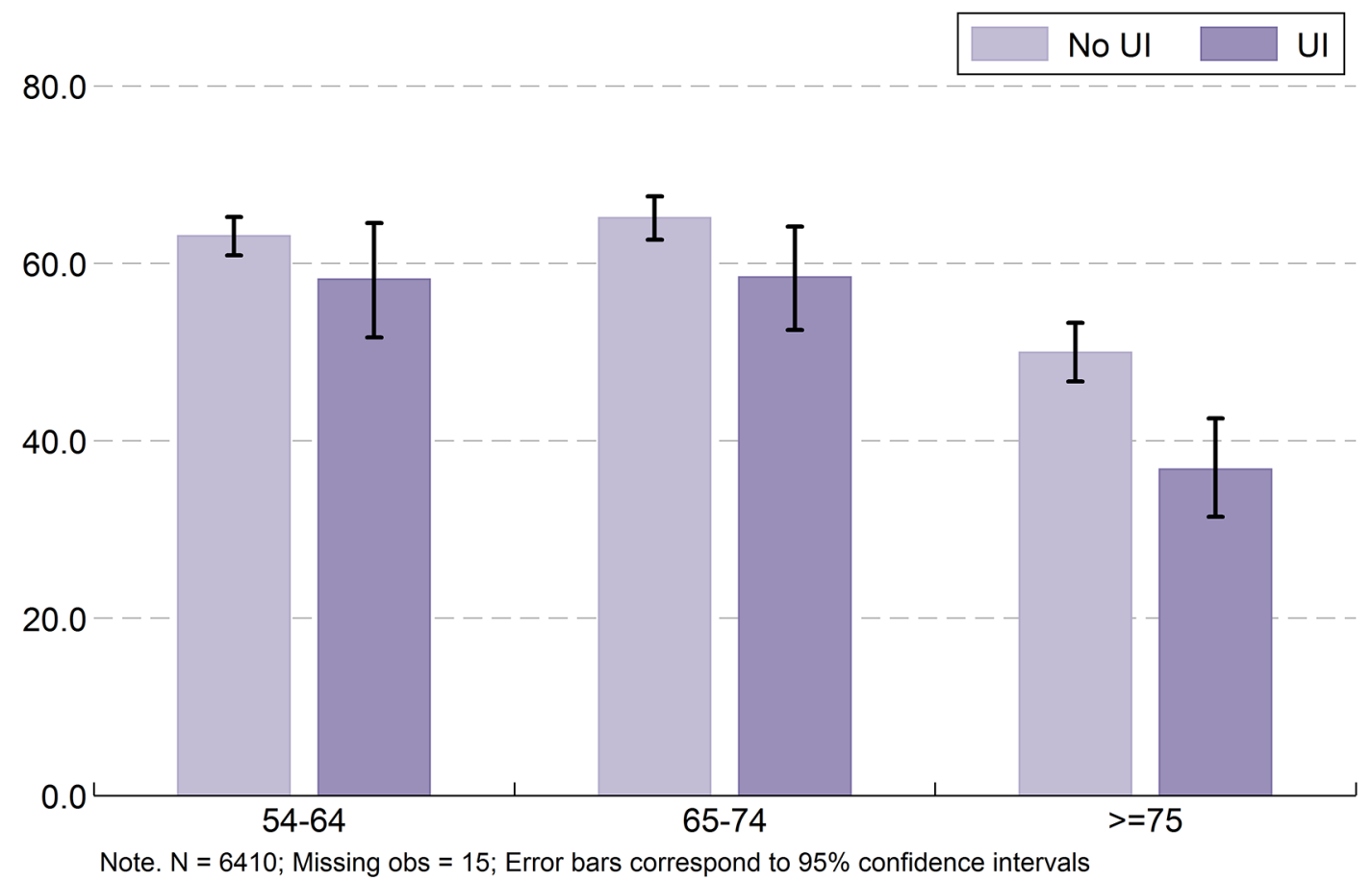


\section{Urinary incontinence and quality of life}

Older adults with UI report lower quality of life compared to those without UI (24 versus $27)$. This is observed in both men and women with the exception of men aged 75 years and over (Figure 7.12).

Figure 7.12: Mean quality of life score (CASP-12), by urinary incontinence, age group and sex

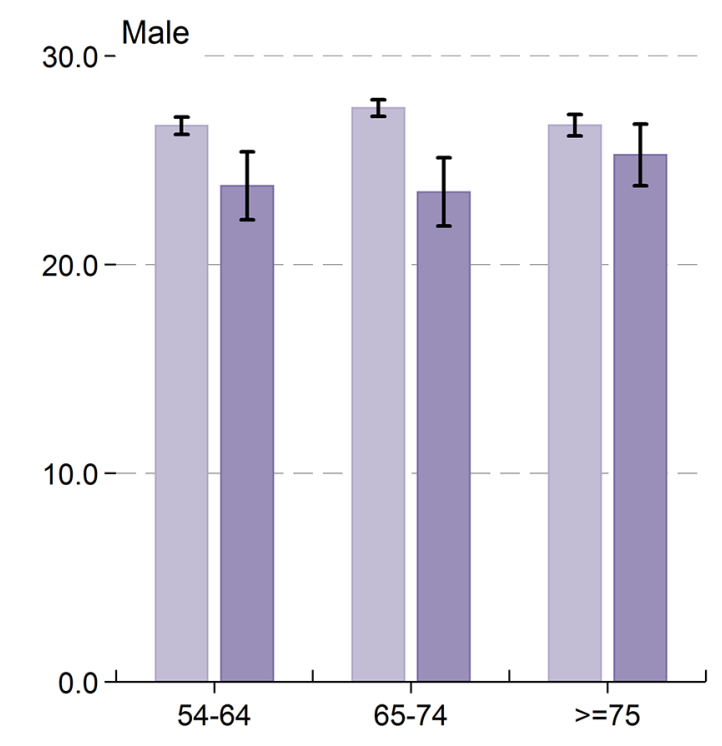

Female

No UI $\square$ UI

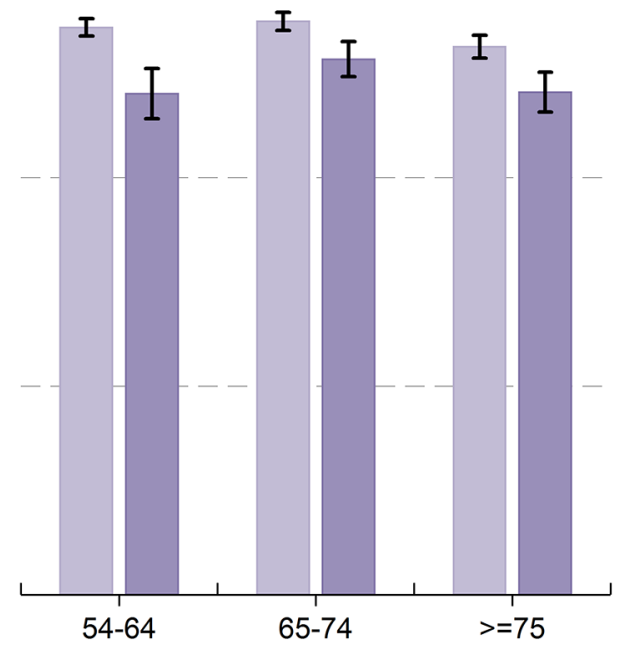

Note. $N=4909$; Missing obs $=1516$; Error bars correspond to $95 \%$ confidence intervals 


\section{Urinary incontinence and mood}

Ul also negatively impacts on a person's mood, reflected in a higher depressive symptoms score in men (4.9 versus 2.7) and women (5.5 versus 3.4) who experience UI compared to those who do not. Higher depression scores are observed across all age groups although, similar to the findings for quality of life, the impact of UI on mood appears to lessen with advancing age (Figure 7.13).

Figure 7.13: Mean depressive symptoms score (CES-D8), by urinary incontinence, age group and sex
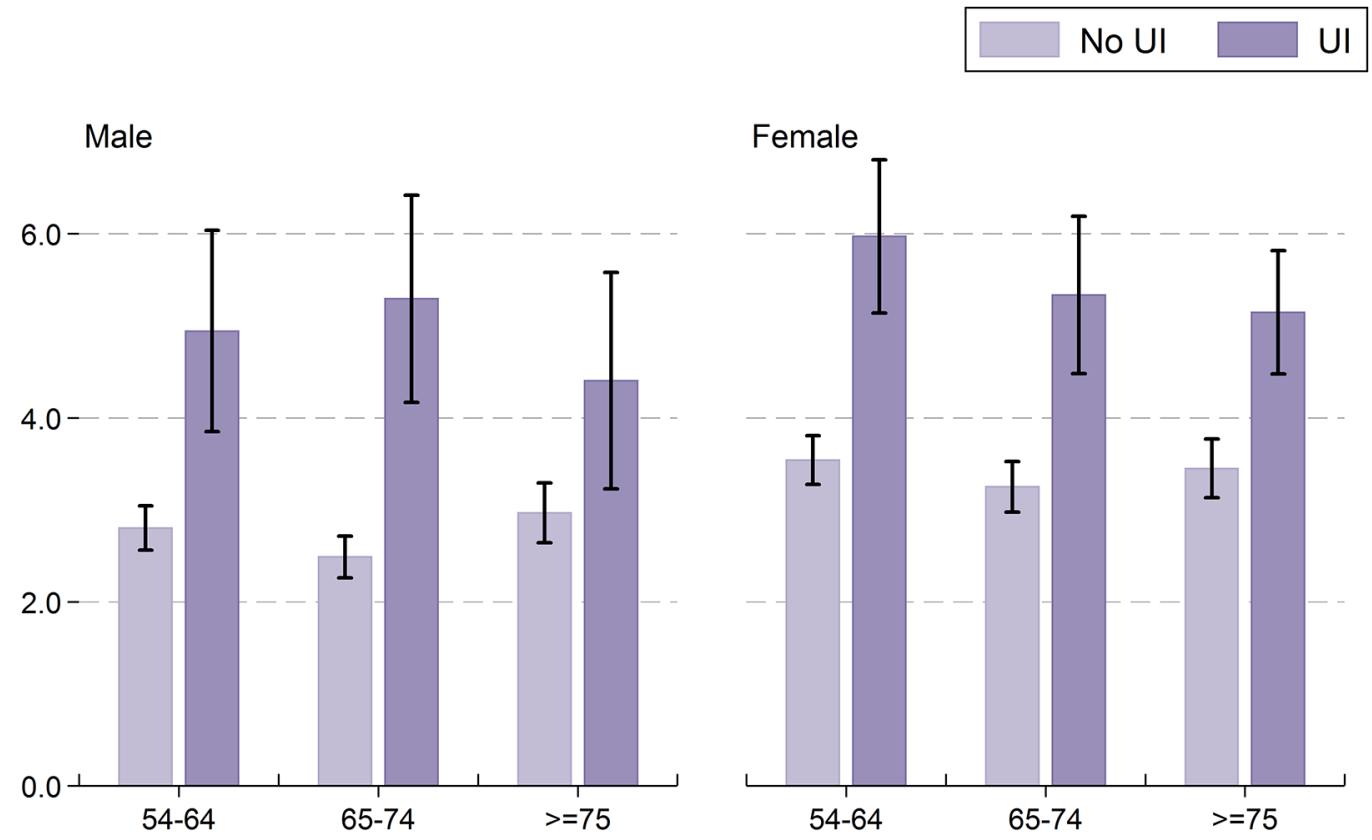

Note. $\mathrm{N}=6264$; Missing obs $=161$; Error bars correspond to $95 \%$ confidence intervals 


\subsubsection{Conclusion}

One in seven older adults in Ireland experiences UI. Women are more likely to be affected than men, and the prevalence increases markedly with age in both sexes. The presence of UI has a negative impact on quality of life, mood and social participation. Despite a high burden of symptoms, and the availability of treatment strategies to reduce that burden, only 3 out of 5 older adults in Ireland report their symptoms to a doctor, nurse or other health care professional. Only by raising awareness of UI, and challenging the notion that $\mathrm{UI}$ is an inevitable part of ageing, will we improve recognition and management of this condition. Importantly, efforts should focus on modifying risk factors for UI such as smoking and obesity; the latter identified by previous TILDA research as a major public health challenge among older adults in Ireland (16). 


\subsection{Hearing loss}

\subsubsection{Introduction}

Older people often "put up" with hearing loss for several years before seeking any treatment. During that time, they are at higher risk of a number of important adverse consequences of hearing loss, such as falls (17), cognitive dysfunction (18) and diminished quality of life (19). It is possible to reverse some of these negative effects with the use of hearing aids, resulting in improved social functioning, quality of life and depression symptoms (20). It is therefore important to identify individuals with hearing impairment early, so that they can potentially avoid complications of hearing loss. TILDA participants were asked (i) whether they felt that they had hearing loss, (ii) to rate their hearing as excellent, very good, good, fair or poor, and (iii) if they used a hearing aid some or all of the time. Finally, we examined the negative consequences of hearing loss. 


\subsubsection{Prevalence of hearing loss}

Over one third of older adults (37\%) have experienced hearing loss and this proportion is higher in men than women ( $41 \%$ versus $32 \%)$. Hearing loss is much more common at older age, exceeding 50\% among individuals aged 75 years and over. This age-related pattern of hearing loss is seen in both men and women (Figure 7.14).

Figure 7.14: Prevalence of self-rated hearing loss, by age group and sex

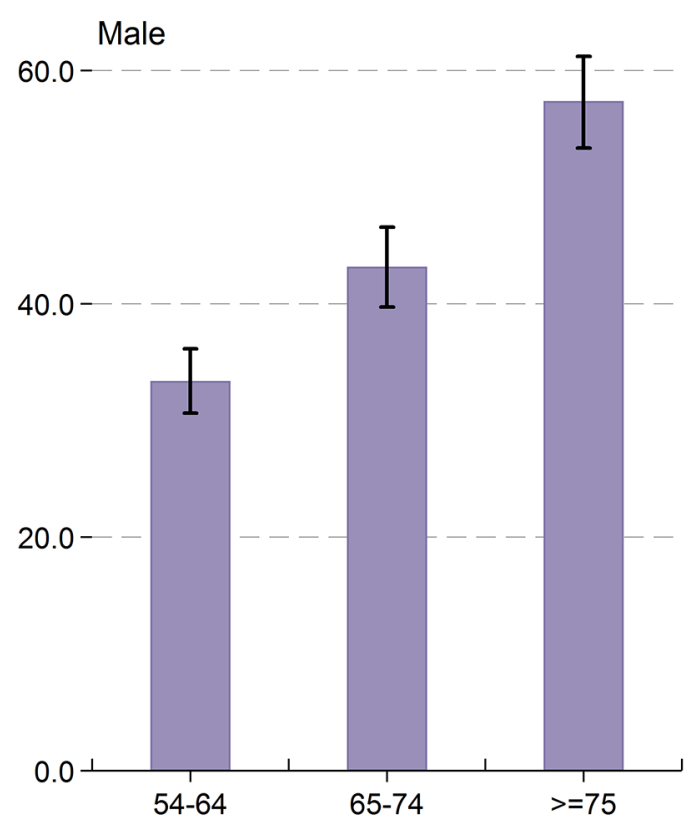

Female

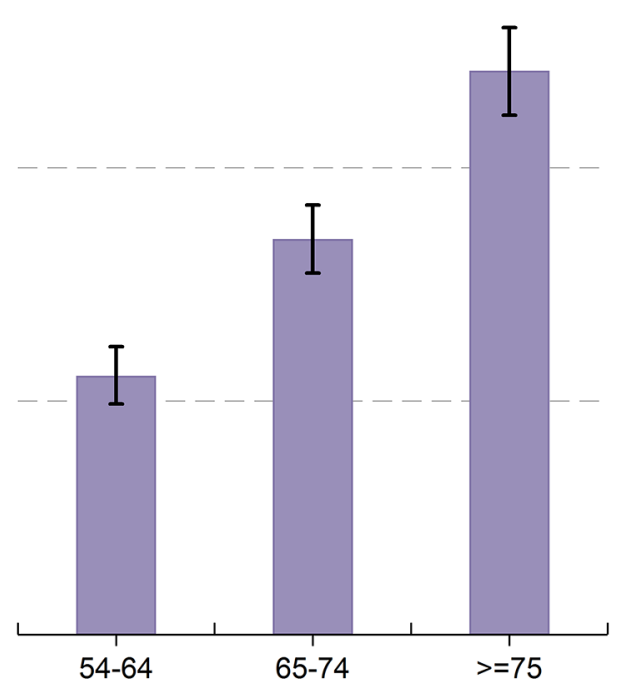

Note. $\mathrm{N}=6407$; Missing obs = 18; Error bars correspond to $95 \%$ confidence intervals

\subsubsection{Self-rated hearing}

One in 6 older adults in Ireland rate their hearing as either "poor" or "fair" and men are more likely than women to do so (19\% versus $13 \%)$. This difference between men and women is most prominent between the ages of 54 and 64 years. This also increases with advancing age. 1 in 10 adults aged 54-64 years report poor or fair hearing, and this figure increases to 1 in 4 adults aged 75 years and over (Figure 7.15). 
Figure 7.15: Self-rated hearing, by age group and sex

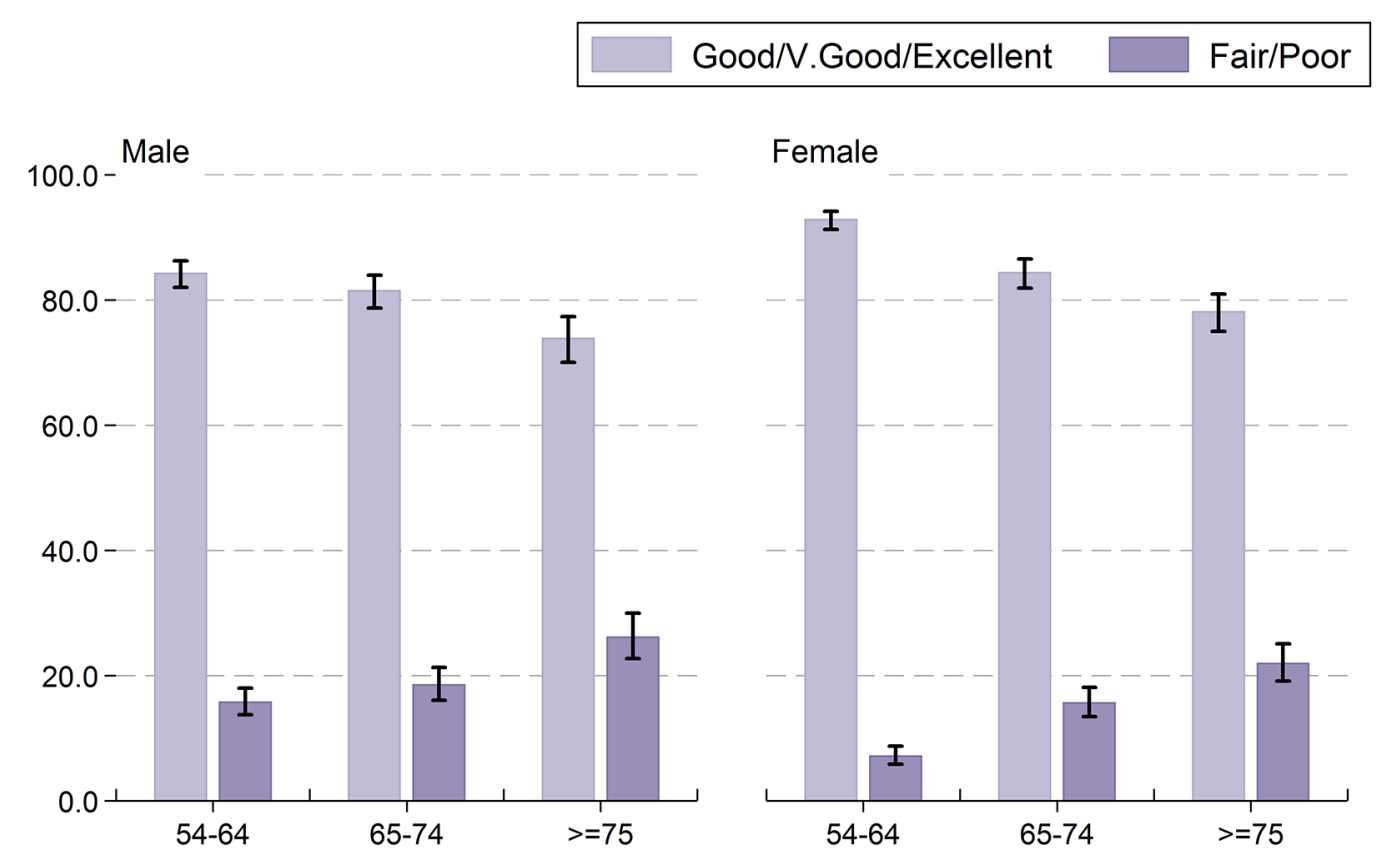

Note. $\mathrm{N}=6307$; Missing obs $=118$; Error bars correspond to $95 \%$ confidence intervals

\subsubsection{Use of hearing aids}

Despite the high prevalence of self-reported hearing loss, the use of hearing aids is low in the general population, which is consistent with other studies (21). Overall, $8 \%$ of older adults in Ireland use a hearing aid some or all of the time. Men are more likely to use a hearing aid compared to women ( $9 \%$ versus $7 \%$ ). The need for a hearing aid increases rapidly with age, in both sexes, from $3 \%$ in adults aged $54-64$ years to $19 \%$ in those aged 75 years and over. Only one in five older adults in Ireland (21\%) who report fair or poor self-rated hearing use a hearing aid. Several barriers to hearing aid use have been identified, including comfort, lack of support or instruction in how to use and maintain the device, appearance and cost (22). In Ireland, medical card holders can avail of a hearing aid free of charge. Hearing aid use is 2 -fold higher among medical card holders with hearing loss $(27 \%)$ compared to those without a medical card $(14 \%)$. 


\subsubsection{Impact of hearing loss}

\section{Difficulty following a conversation}

TILDA participants were asked if they have difficulty following a conversation, either with one person or with four people. One in 20 older adults in Ireland have at least some difficulty following a conversation with one person and this increases with age, affecting one in 10 adults aged 75 years and over. More individuals experience some or a lot of difficulty following a conversation with four people (29\%). Again, men are more likely to experience difficulty than women (32\% versus $25 \%)$, and difficulty is highest among adults aged 75 years and over (43\%) (Figure 7.16$)$.

Figure 7.16: Difficulty following a conversation with four people, by age group and sex

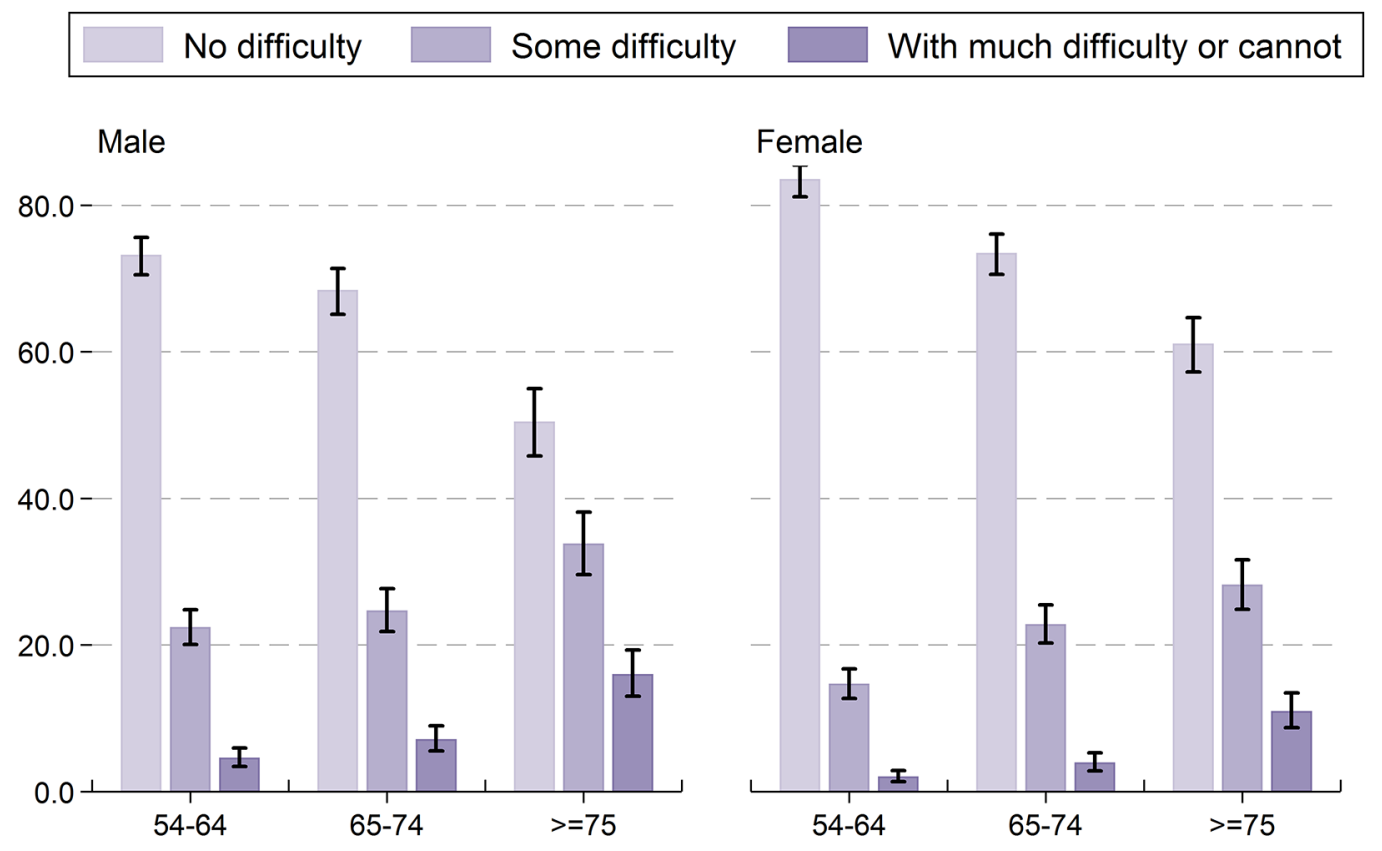

Note. $\mathrm{N}=6305 ;$ Missing obs $=120 ;$ Error bars correspond to $95 \%$ confidence intervals 


\section{Hearing loss and quality of life}

Individuals who report fair or poor hearing have lower CASP-12 scores indicating reduced quality of life compared to those who rate their hearing as good, very good or excellent. This pattern is evident in men and women of all age groups except women aged 54-64 years (Figure 7.17).

Figure 7.17: Mean quality of life score (CASP-12), by self-rated hearing, age group and sex

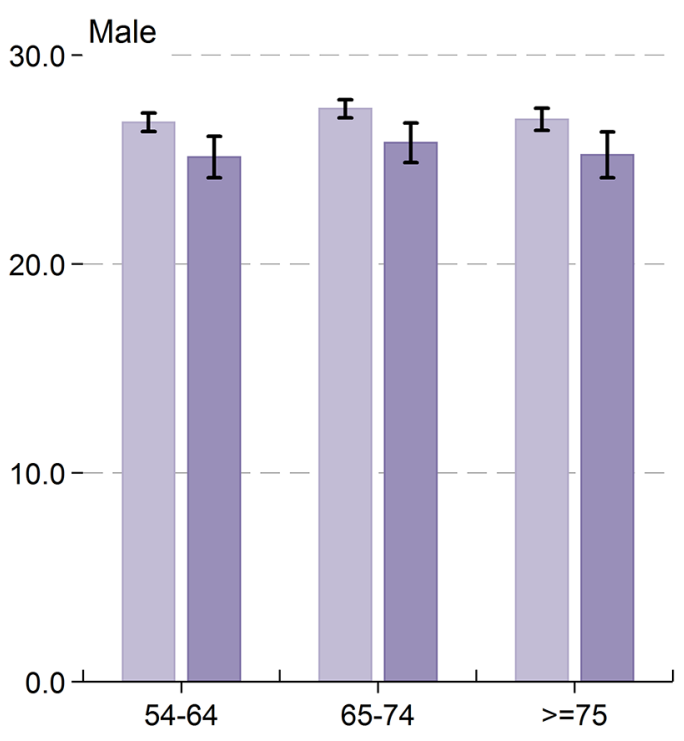

Female

Note. $\mathrm{N}=4913$; Missing obs $=1512$; Error bars correspond to $95 \%$ confidence intervals 


\section{Hearing loss and active social participation}

Older adults who rate their hearing as fair or poor have reduced active social participation compared to those with excellent, good or very good hearing ( $55 \%$ versus $62 \%$ ). This difference is most evident in women aged 65-74 years (Figure 7.18).

Figure 7.18: Active social participation, by self-rated hearing, age group and sex

\section{Good/V.Good/Excellent}

Fair/Poor

$80.0-$ Male

Female
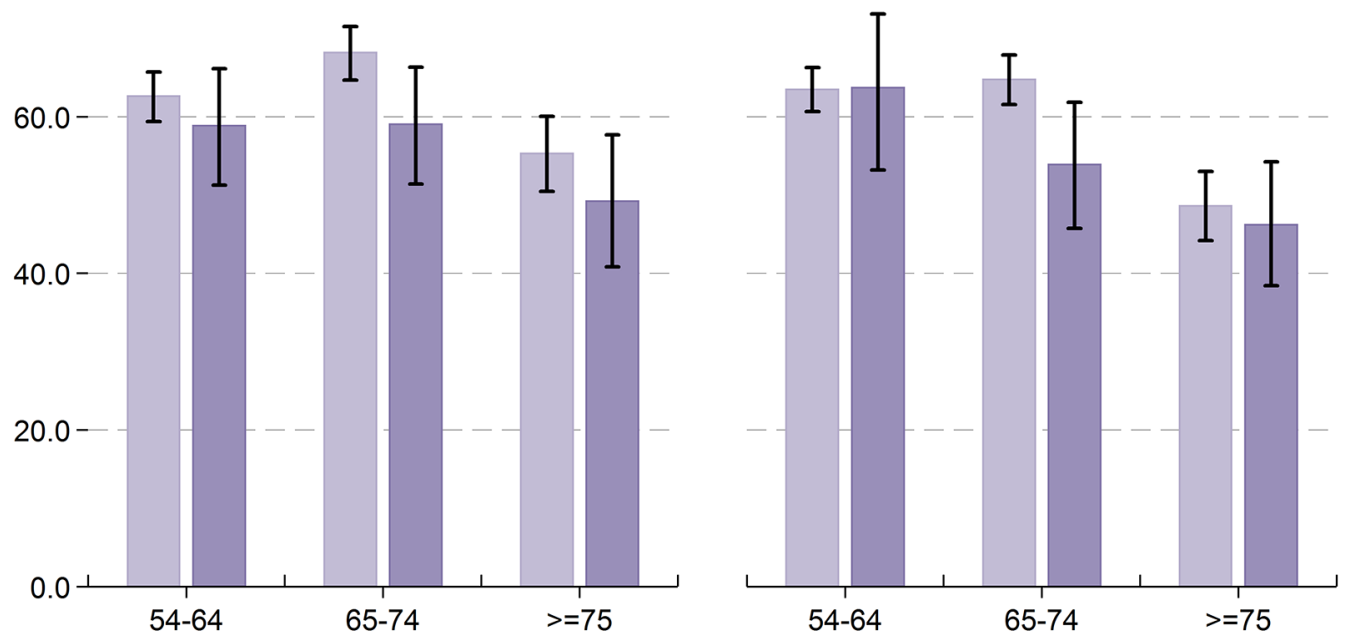

Note. $\mathrm{N}=6307 ;$ Missing obs $=118 ;$ Error bars correspond to $95 \%$ confidence intervals 


\section{Hearing loss and mood and loneliness}

Older adults with fair or poor self-rated hearing tend to have a higher number of depressive symptoms (4.2 versus 3.2) compared to those with better self-rated hearing. This association is observed in both men and women, and across age categories (Figure 7.19).

Figure 7.19: Mean depressive symptoms score (CES-D8) by self-rated hearing, age group and sex

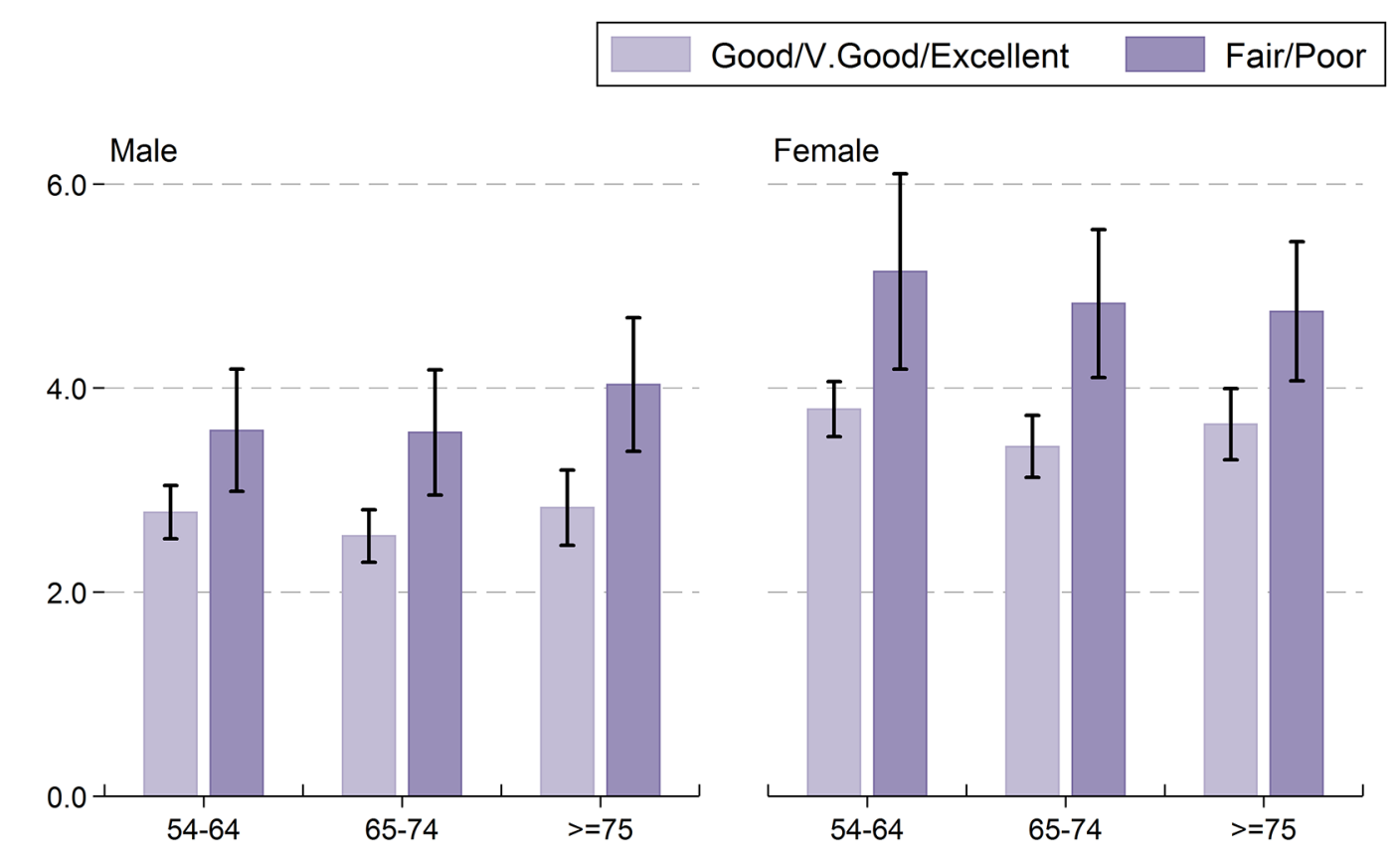

Note. $\mathrm{N}=6267 ;$ Missing obs $=158 ;$ Error bars correspond to $95 \%$ confidence intervals

Symptoms of loneliness were assessed using the University of California-Los Angeles (UCLA) Loneliness Scale (23). Scores can range from 0 (not lonely) to 10 (extremely lonely). Poorer self-rated hearing is associated with a greater severity of loneliness symptoms (2.2 versus 1.7). This is consistent with the observation that older adults with hearing difficulties are less likely to engage in active social participation (Figure 7.18). The burden of loneliness associated with hearing loss appears to become greater with age, particularly in women aged 75 years and over (Figure 7.20). 
Figure 7.20: UCLA loneliness score, by self-rated hearing, age group and sex

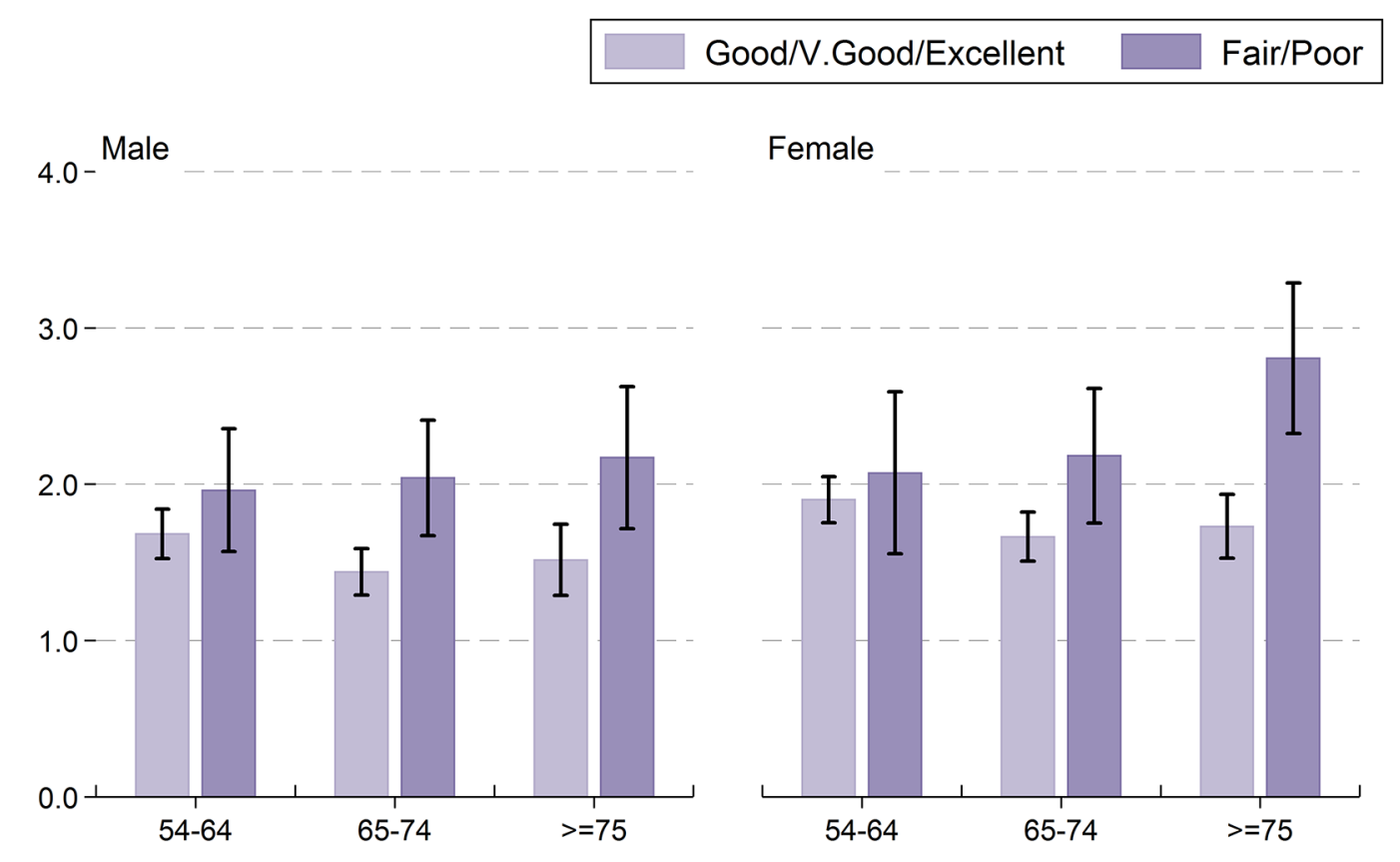

Note. $\mathrm{N}=5204 ;$ Missing obs $=1221$; Error bars correspond to $95 \%$ confidence intervals

\subsubsection{Conclusion}

Hearing loss is highly prevalent among older adults in Ireland, particularly in men. It is estimated that one in two older adults aged 75 years and over has experienced at least some hearing loss. Older men in particular experience difficulty following a conversation due to hearing loss, and are greatly limited in their ability to follow conversations with several people. Poorer self-rated hearing contributes to lower social participation and quality of life, and more loneliness and depressive symptoms. Although not successful in everyone, hearing aids can improve several aspects of life that have been compromised by hearing loss. Despite this, and availability of financial support for hearing aids in Ireland, the use of hearing aids remains low in the general population of older adults. Screening for hearing loss at an earlier stage, and promoting the use of hearing aids, has the potential to improve the ageing experience for many older adults. 


\subsection{Depression}

\subsubsection{Introduction}

Depression is defined as pervasive and persistent low mood that is accompanied by low self-esteem and loss of interest in normally enjoyable activities. It is now the second leading cause of disability worldwide (24).

Late life depression (LLD) is depressive illness with onset in later life, or with an earlier onset but persisting into later life. LLD is different to depression presenting earlier in life on several levels. Older people with LLD report more somatic complaints than younger people, such as fatigue and low energy, and symptoms of low mood are often less prominent (25). While later life is generally a time of reasonably good health and happiness, LLD can also occur on a background of different social factors such as bereavement and social isolation. LLD also confers a higher risk of completed suicide than early onset depression.

Studies have also demonstrated that depression in later life is more common in those with significant medical illness and functional impairment (26). Depression can intensify these limitations, and carries with it significant levels of morbidity and mortality (27), as well as further functional limitations, independent of underlying illnesses (28).

Given the significant impact it can have on the health and quality of life of the older person, it is crucial that we understand the true burden of LLD at a population level. The Composite International Diagnostic Interview (CIDI), a structured diagnostic interview for assessment of mental health disorders was used to estimate the incidence of major depressive episodes in the older Irish population (29). In addition, the CES-D8, a commonly used selfreport measure of depressive symptoms validated for use in an older population was used to measure prevalence of depressive symptoms (10). 


\subsubsection{Prevalence of major depressive episode within last 12 months}

Overall, 1 in 20 older adults (5\%) meet criteria for a major depressive episode within the last 12 months. Over two thirds (70\%) of older people with a major depressive episode are female (Figure 7.21).

Figure 7.21: Major depressive episode within last 12 months, by age group and sex
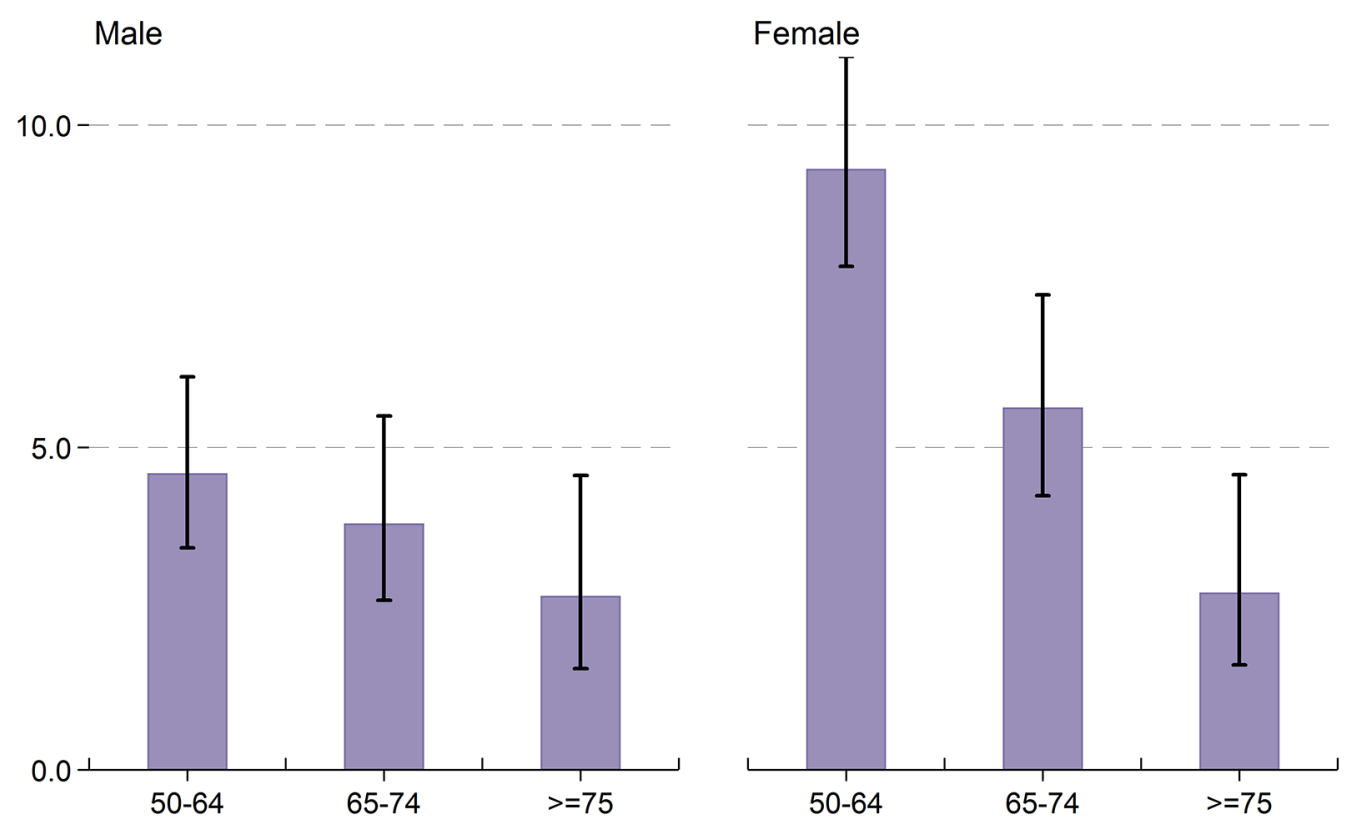

Note. $\mathrm{N}=6487$; Missing obs $=131$; Error bars correspond to $95 \%$ confidence intervals 


\subsubsection{Level of depressive symptoms}

The level of depressive symptoms in older adults is shown in Figure 7.22, with higher scores in women consistently across age groups (Figure 7.22).

Figure 7.22: Mean depressive symptoms score (CES-D8), by age group and sex
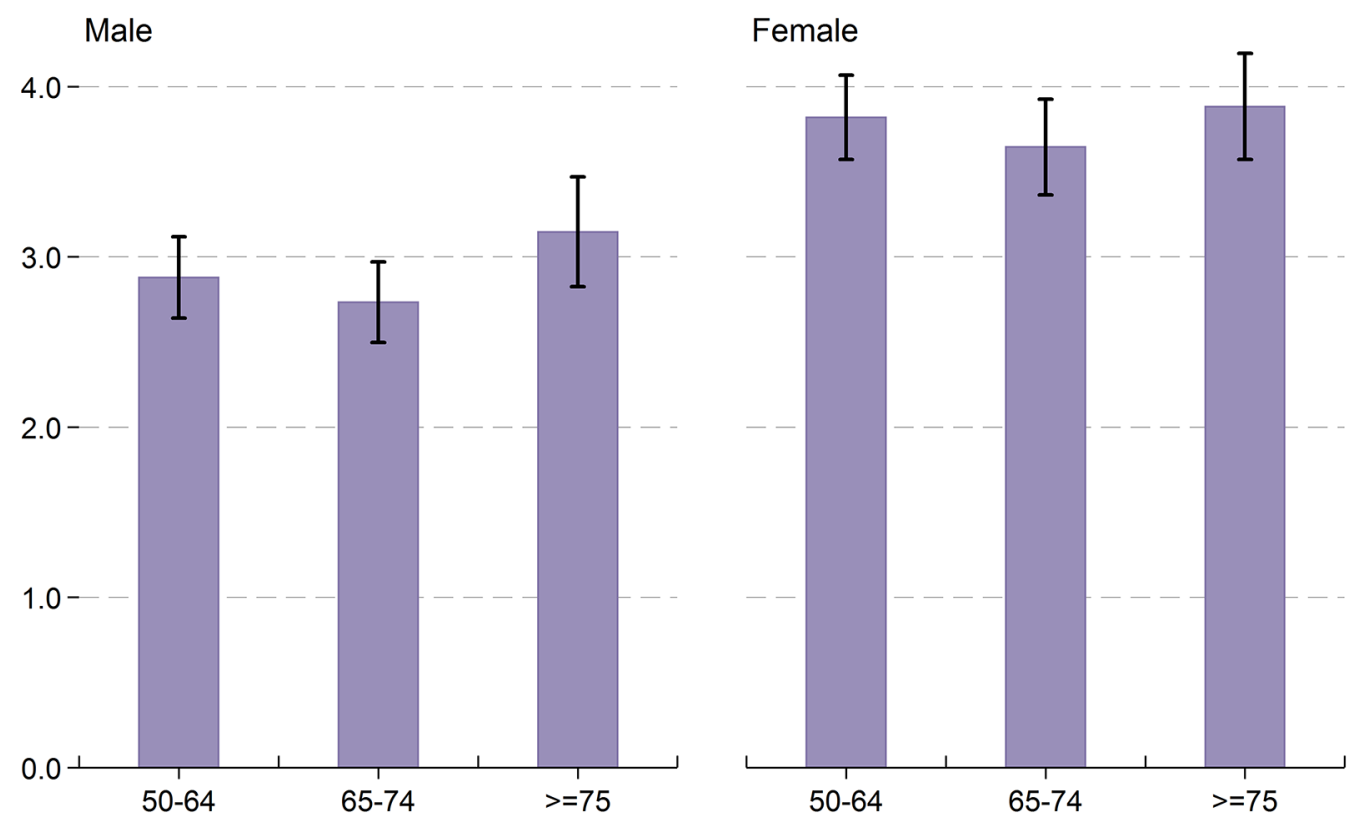

Note. $\mathrm{N}=6464 ;$ Missing obs $=154$; Error bars correspond to $95 \%$ confidence intervals

\subsubsection{Depressive symptoms, disability and self-rated health}

Depressive symptoms are strongly associated with levels of disability and self-rated health. Older people with one or more impairments in IADLs have increased depressive symptoms compared to those who have no IADLs. Furthermore, over one third of older people who rate their health as 'poor' have increased depressive symptoms, compared to those who rate their health as 'excellent'. 


\subsubsection{Treatment of depression}

Antidepressant therapy is an efficacious medical treatment for depression in older people, and alongside cognitive behavioural therapy forms the mainstay of treatment for this condition. However, only one in three (32\%) older people with increased depressive symptoms (CES-D8 score $\geq 10$ ) are currently prescribed antidepressant therapy.

There are several possible reasons for this disparity. Older people are less likely to report depressive symptoms to a healthcare professional than younger counterparts, and therefore LLD often goes undiagnosed (30). This may in part be due to the stigma surrounding mental health issues or the incorrect assumption that low mood, alongside other symptoms such as memory loss, UI or pain is a 'normal' part of ageing. Depression may therefore incorrectly be seen as an inevitable response to some of the challenges of later life, and appropriate therapy is not provided to the older person. Additionally, because depression in later life often presents differently to earlier onset depression, it may not be identified correctly even when older people present with symptoms to a healthcare professional.

\subsubsection{Conclusion}

Overall 1 in 20 older adults in Ireland had a major depressive episode in the last 12 months and only $32 \%$ of older people with increased CES-D8 score are prescribed appropriate medical therapy for depression. Given projected future demographic changes, in conjunction with the detrimental effect that depression can have on the health and independence of older people, the burden of LLD is likely to increase significantly in the near future.

It is important therefore to raise awareness of LLD among older people themselves, as well as their families and healthcare professionals involved in the care of older people, with particular focus on the fact that LLD is not an inevitable consequence of ageing and that effective treatment is available.

It is also crucial that, in the same way campaigns have addressed the issue of mental health of younger people; similar efforts are made to reduce the stigma around mental health in later life and encourage older people to seek help from a healthcare professional when they are experiencing symptoms of depression. 


\subsection{Conclusion}

Healthy ageing encompasses physical, social and mental wellbeing, as well as independence and quality of life (31). This chapter highlights the need for appropriate management of a number of "unseen" or underemphasised conditions that can be mistaken as part of the "normal" ageing process and have significant functional consequences for older adults. These conditions are treatable and strategies to maximise reporting to healthcare workers, and to provide adequate management strategies for conditions such as urinary incontinence, pain, hearing loss and depression, are required to ensure optimal physical, mental and social wellbeing in older adults in Ireland. 


\section{References}

1. Goldberg DS MS. Pain as a global public health priority. BMC Public Health. 2011;11:770.

2. Vos T, Flaxman AD, Naghavi M, Lozano R, Michaud C, Ezzati M, et al. Years lived with disability (YLDs) for 1160 sequelae of 289 diseases and injuries 19902010: a systematic analysis for the Global Burden of Disease Study 2010. Lancet. 2012;380(9859):2163-96.

3. O'Sullivan K, Kennedy N, Purtill H, Hannigan A. Understanding pain among older persons: Part 1-the development of novel pain profiles and their association with disability and quality of life. Age Ageing. 2016.

4. Abdulla A, Adams N, Bone M, Elliott AM, Gaffin J, Jones D, et al. Guidance on the management of pain in older people. Age Ageing. 2013;42 Suppl 1:i1-57

5. Gibson SJ, Lussier D. Prevalence and relevance of pain in older persons. Pain Med. 2012;13 Suppl 2:S23-6.

6. Herr KA, Garand L. Assessment and measurement of pain in older adults. Clin Geriatr Med. 2001;17(3):457-78, vi.

7. Kennedy N, O'Sullivan K, Hannigan A, Purtill H. Understanding pain among older persons: Part 2-the association between pain profiles and healthcare utilisation. Age Ageing. 2016.

8. Sexton E, King-Kallimanis BL, Conroy RM, Hickey A. Psychometric evaluation of the CASP-19 quality of life scale in an older Irish cohort. Qual Life Res. 2013;22(9):254959.

9. Wiggins RD, Netuveli G, Hyde M, Higgs P, Blane D. The evaluation of a selfenumerated scale of quality of life (CASP-19) in the context of research on ageing: A combination of exploratory and confirmatory approaches. Soc Indic Res. 2008;89(1):61-77. 
10. Karim J, Weisz R, Bibi Z, Rehman SU. Validation of the Eight-Item Center for Epidemiologic Studies Depression Scale (CES-D) Among Older Adults. Curr Psychol. 2015;34(4):681-92.

11. Abrams P, Cardozo L, Fall M, Griffiths D, Rosier P, Ulmsten U, et al. The standardisation of terminology of lower urinary tract function: report from the Standardisation Sub-committee of the International Continence Society. Neurourol Urodyn. 2002;21(2):167-78.

12. Hampel C, Wienhold D, Benken N, Eggersmann C, Thuroff JW. Definition of overactive bladder and epidemiology of urinary incontinence. Urology. 1997;50(6A Suppl):4-14; discussion 5-7.

13. Dugan E, Roberts CP, Cohen SJ, Preisser JS, Davis CC, Bland DR, et al. Why older community-dwelling adults do not discuss urinary incontinence with their primary care physicians. J Am Geriatr Soc. 2001;49(4):462-5.

14. Horrocks S, Somerset M, Stoddart H, Peters TJ. What prevents older people from seeking treatment for urinary incontinence? A qualitative exploration of barriers to the use of community continence services. Fam Pract. 2004;21(6):689-96.

15. Coyne KS, Wein AJ, Tubaro A, Sexton CC, Thompson CL, Kopp ZS, et al. The burden of lower urinary tract symptoms: evaluating the effect of LUTS on health-related quality of life, anxiety and depression: EpiLUTS. BJU Int. 2009;103 Suppl 3:4-11.

16. Leahy S, Nolan A, O' Connell J \& Kenny RA. Obesity in an ageing society: implications for health, physical function and health service utilisation. TILDA. 2014

17. Lin FR, Ferrucci L. Hearing loss and falls among older adults in the United States. Arch Intern Med. 2012;172(4):369-71.

18. Lin FR, Ferrucci L, Metter EJ, An Y, Zonderman AB, Resnick SM. Hearing loss and cognition in the Baltimore Longitudinal Study of Aging. Neuropsychology. 2011;25(6):763-70.

19. Chia EM, Wang JJ, Rochtchina E, Cumming RR, Newall P, Mitchell P. Hearing impairment and health-related quality of life: the Blue Mountains Hearing Study. Ear Hear. 2007;28(2):187-95. 
20. Mulrow CD, Aguilar C, Endicott JE, Tuley MR, Velez R, Charlip WS, et al. Qualityof-life changes and hearing impairment. A randomized trial. Ann Intern Med. 1990;113(3):188-94.

21. Chien W, Lin FR. Prevalence of Hearing Aid Use Among Older Adults in the United States. Arch Intern Med. 2012;172(3):292-3.

22. McCormack $A$, Fortnum $H$. Why do people fitted with hearing aids not wear them? Int $J$ Audiol. 2013;52(5):360-8.

23. Russell D. The UCLA Loneliness Scale (Version 3): Reliability, validity, and factor structure. J Pers Assess 1996;66:20-40.

24. Ferrari AJ, Charlson FJ, Norman RE, Patten SB, Freedman G, Murray CJ, et al. Burden of depressive disorders by country, sex, age, and year: findings from the global burden of disease study 2010. PLoS Med. 2013;10(11):e1001547.

25. Fiske A, Wetherell JL, Gatz M. Depression in Older Adults. Annu Rev Clin Psycho. 2009;5:363-+.

26. Noel PH, Williams JW, Jr., Unutzer J, Worchel J, Lee S, Cornell J, et al. Depression and comorbid illness in elderly primary care patients: impact on multiple domains of health status and well-being. Ann Fam Med. 2004;2(6):555-62.

27. Schulz R, Beach SR, Ives DG, Martire LM, Ariyo AA, Kop WJ. Association between depression and mortality in older adults - The Cardiovascular Health Study. Arch Intern Med. 2000;160(12):1761-8.

28. Penninx BW, Guralnik JM, Ferrucci L, Simonsick EM, Deeg DJ, Wallace RB. Depressive symptoms and physical decline in community-dwelling older persons. JAMA. 1998;279(21):1720-6.

29. Robins LN, Wing J, Wittchen HU, Helzer JE, Babor TF, Burke J, et al. The Composite International Diagnostic Interview - an Epidemiologic Instrument Suitable for Use in Conjunction with Different Diagnostic Systems and in Different Cultures. Arch Gen Psychiat. 1988;45(12):1069-77. 
30. Roman MW, Callen BL. Screening instruments for older adult depressive disorders: updating the evidence-based toolbox. Issues Ment Health Nurs. 2008;29(9):924-41.

31. Ell K. Depression care for the elderly: reducing barriers to evidence-based practice. Home Health Care Serv Q. 2006;25(1-2):115-48.

32. Peel N, Bartlett $H$, McClure R. Healthy ageing: how is it defined and measured? Australas J Ageing. 2004;23(3):115-9. 
Appendix 7A: Tables on Prevalence and Impact of Chronic Debilitating Disorders

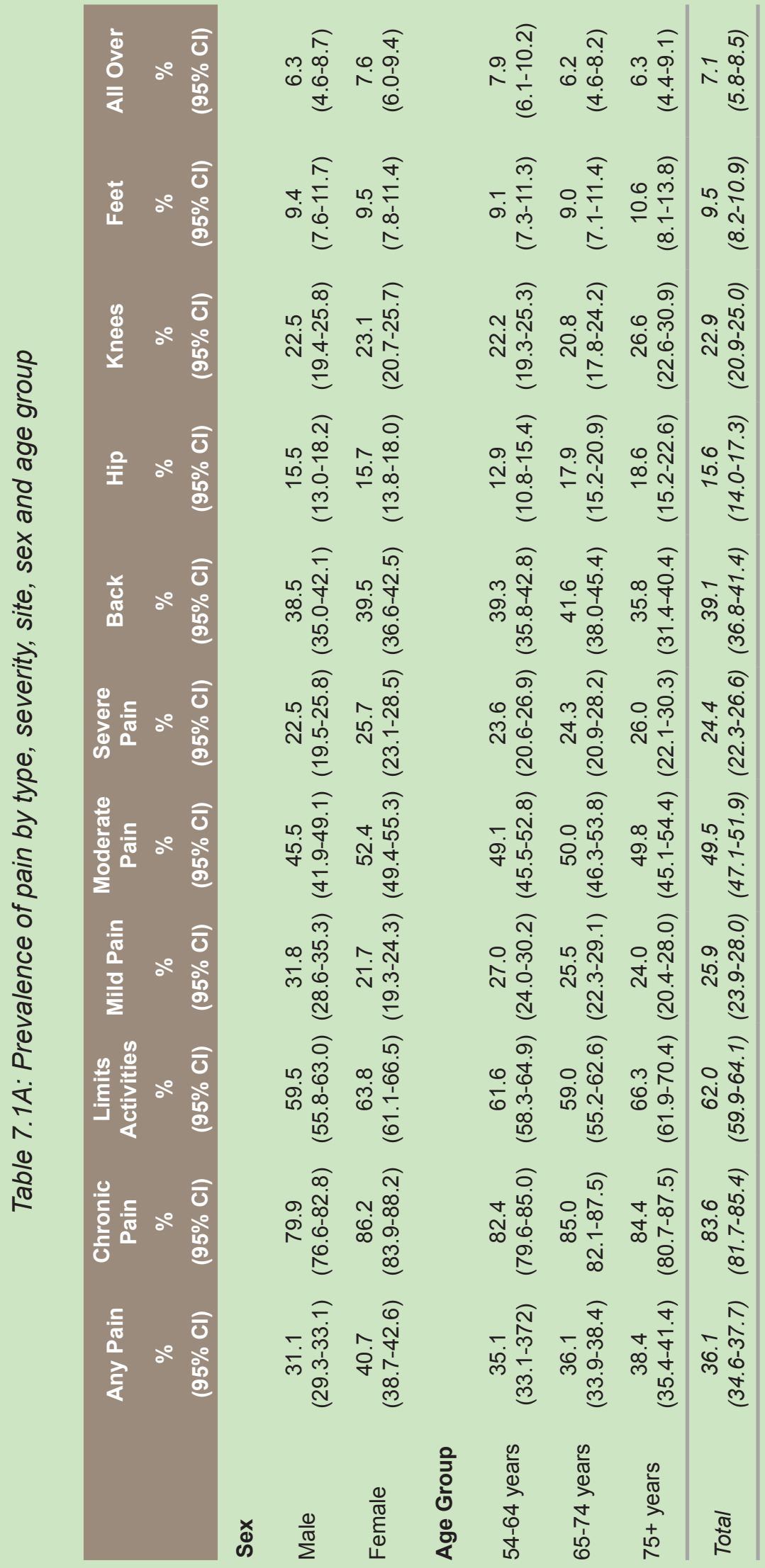


Table 7.2A: Prevalence of limiting pain by pain site

\begin{tabular}{lcccc} 
& \multicolumn{2}{c}{ Not Limiting } & \multicolumn{2}{c}{ Limiting Pain } \\
& $\%$ & $(95 \% \mathrm{Cl})$ & $\%$ & $(95 \% \mathrm{CI})$ \\
Back Pain & 32.0 & $(28.6-35.6)$ & 68.0 & $(64.4-71.4)$ \\
Hip Pain & 36.2 & $(30.8-41.8)$ & 63.9 & $(58.2-69.2)$ \\
Knee Pain & 38.2 & $(33.8-42.8)$ & 61.8 & $(57.2-66.2)$ \\
Foot Pain & 36.8 & $(30.1-44.1)$ & 63.2 & $(55.9-69.9)$ \\
All Over Pain & 23.4 & $(16.4-32.3)$ & 76.6 & $(67.7-83.7)$
\end{tabular}

Table 7.3A: Mean number of GP visits by pain site

\begin{tabular}{lccc} 
& \multicolumn{3}{c}{$\begin{array}{c}\text { Mean number of GP visits in the last year by site of } \\
\text { greatest severity of pain } \\
(95 \% \mathrm{CI})\end{array}$} \\
No pain site & 3.17 & $(3.1-3.3)$ & $\mathrm{N}$ \\
Back Pain & 5.07 & $(4.5-5.6)$ & 5096 \\
Hip Pain & 4.45 & $(3.8-5.1)$ & 220 \\
Knee Pain & 4.89 & $(4.4-5.4)$ & 380 \\
Feet Pain & 5.47 & $(4.7-6.3)$ & 182 \\
All Over Pain & 7.58 & $(5.9-9.3)$ & 151 \\
Other Pain & 5.09 & $(4.7-5.5)$ & 681
\end{tabular}


7 Prevalence and Impact of Chronic Debilitating Disorders

Table 7.4A: Mean quality of life score (CASP-12) by sex and age group

\begin{tabular}{|c|c|c|c|c|c|c|}
\hline \multirow{2}{*}{ 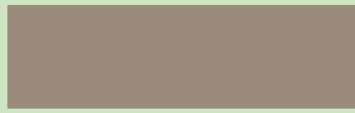 } & \multicolumn{3}{|c|}{ No Pain } & \multicolumn{3}{|c|}{ Pain } \\
\hline & Mean & $(95 \% \mathrm{Cl})$ & $\mathbf{N}$ & Mean & (95\% Cl) & $\mathbf{N}$ \\
\hline
\end{tabular}

\section{Gender}

Male

27.5

$(27.2-27.8)$

1612

$24.8 \quad(24.3-25.3)$

648

Female

28.0

$(27.8-28.3)$

1635

24.5

(24.1-24.9) 1015

Age Groups

54-65

65-74

$27.9 \quad(27.6-28.3) \quad 1419$

$24.4 \quad(23.8-24.9) \quad 717$

$75+$

28.0

$(27.7-28.4)$

1109

$25.5 \quad(25.0-26.0) \quad 576$

$27.1 \quad(26.6-27.5) \quad 616$

$24.5 \quad(23.9-25.0) \quad 332$

Total

$27.8 \quad(27.6-28.0) \quad 3247$

$24.6 \quad(24.3-25.0) \quad 1663$ 
